\title{
Narrativas de Madres: acerca de las concepciones y prácticas del cuidado en la primera infancia con discapacidad y su incidencia en la calidad de vida en la localidad de San Cristóbal ${ }^{\star}$
}

Narratives of Mothers: about concepts and practices in the care of early childhood

with disabilities and their impact on quality of life in the locality of San Cristobal

Alba Viviana Herrera H.**

Recibido: 11 de mayo de 2015

Revisado: 2 de junio de 2015

Aprobado: 8 de junio de 2015

* Artículo de investigación resultado del proyecto la primera infancia con discapacidad y su incidencia en la calidad de vida.

** Licenciada en Educación Especial de la Fundación Universitaria Los Libertadores. Magíster en Estudios y Gestión del Desarrollo, Facultad de Ciencias Económicas y Sociales de la Universidad de La Salle. Artículo realizado como parte del proyecto de investigación de madres en la primera infancia. Correo: halbaviviana@yahoo.es 


\section{Resumen}

Este artículo es el resultado de la investigación desarrollada en la localidad cuarta San Cristóbal de la ciudad de Bogotá. El objetivo de esta fue comprender las concepciones y prácticas de madres en el cuidado de niños y niñas con discapacidad en primera infancia y cómo estas inciden en la calidad de vida de sus familias; se investigaron las narrativas de madres que permitieron una interpretación significativa y reflexiva sobre la vida cotidiana de las cuidadoras de estas familias que están en la búsqueda constante de la garantía de los Derechos Humanos. La investigación fue de carácter cualitativo con enfoque histórico hermenéutico; se realizaron cinco entrevistas semiestructuradas con madres cuidadoras, quienes construyeron sus narrativas a partir de las concepciones y prácticas del cuidado de los niños y niñas con discapacidad, y su incidencia en la calidad de vida. Para comprender las concepciones de las cuidadoras se utilizaron como referentes teóricos a Nussbaum y Sen (1998) y su definición de "calidad de vida". También se retoma a Schalock y Verdugo (2011), quienes definen la categoría de "bienestar". Finalmente, a Nussbaum (2005), que a partir de su concepto de habilidades -habilidad para un examen crítico de uno mismo y de las propias tradiciones ${ }^{2}$, la destreza que debe poseer el ciudadano y la imaginación narrativa-, permite comprender las particularidades de cada una de las familias. Dentro de las conclusiones se destaca la sobrecarga que las madres deben asumir como único miembro de la familia que cuida a los niños y niñas con discapacidad, lo que implica que ellas dejen de lado su desarrollo personal, laboral, social, encontrando barreras actitudinales que condicionan y pueden determinar la calidad de vida.

Palabras clave: calidad de Vida, discapacidad, cuidado, narrativas.

Clasificación JEL: I10, I20, I30

1 La definición del "bienestar" de Schalock y Verdugo (2011) está relacionada con nueve dimensiones: bienestar emocional, relaciones personales, bienestar material, desarrollo material, desarrollo personal, bienestar físico, autodeterminación, de inclusión social y defensa de los derechos.

2 Es aquella capacidad de verse a sí mismo no solo como ciudadanos de alguna región o grupo, sino como seres humanos vinculados a otros por lazos de reconocimiento y mutua preocupación. 


\section{Abstract}

This article is the result of the research carried out in the fourth locality San Cristobal in the city of Bogota. The aim was to understand the concepts and practices of mothers in caring for children with disabilities in early childhood and how these affect the quality of life of their families; the narratives of mothers who allowed a meaningful and reflective interpretation on the daily lives of the caregivers of these families who are in constant search of the guarantee of Human Rights were investigated. The research was of qualitative naure with a historical hermeneutical approach; five semi-structured interviews were conducted with caring mothers, who built their narratives from the conceptions and practices in caring for children with disabilities and their impact on quality of life. To understand the concepts of the caregivers, theoretical references to Nussbaum and Sen (1998) and their definition of "quality of life" were used. It also takes up Schalock and Verdugo (2011), who define the category of "well-being"". Finally, Nussbaum (2005), who from her concept of capabilities -capability for a critical examination of oneself and one's own traditions ${ }^{4}$, the skills a citizen must have and the narrative imagination-, allows to understand the particularities of each one of the families. Among the conclusions, the overload that mothers must take on as the only family member who cares for children with disabilities is emphasized, which entails that they put aside their personal, labor, social development, finding attitudinal barriers that condition and can determine the quality of life.

Keywords: Quality of Life, Disability, Care, Narratives.

Glassification JEL: I10, I20, I30

3 The definition of "well-being" of Schalock and Verdugo (2011) is related to nine dimensions: emotional well-being, personal relationships, material well-being, material development, personal development, physical well-being, selfdetermination, social inclusion and defense of rights.

4 Is the ability to see oneself not only as citizens of any region or group, but as human beings connected to others by ties of recognition and mutual concern. 


\section{Introducción}

Esta investigación busca indagar en la comprensión de las concepciones y prácticas de madres acerca del cuidado de los niños y niñas con discapacidad y la incidencia en la calidad de vida de sus familias, ubicadas en la localidad de San Cristóbal de la ciudad de Bogotá. Se indaga por medio de narrativas que permiten referenciar sucesos y acciones que definen el criterio propio de las cuidadoras como únicas conocedoras de las necesidades, satisfacciones y el manejo de la discapacidad en estas familias. Se utilizaron narrativas como estrategia de investigación ya que permiten, tal como Nussbaum lo define:

Entender el mundo desde el punto de vista del otro, siendo esencial para dar cualquier juicio, puesto que no sabremos lo que estamos juzgando, hasta no ver el significado de una acción, según la intención de la persona que la realiza, ni entenderemos el significado de un discurso mientras no conozcamos la importancia de lo que expresa en el contexto de la historia y el mundo social de esa persona. (Nussbaum, 2005, p. 30)

A partir de este ejercicio activo, el cual no solo permitió comprender sino acercarnos a la realidad social de las cuidadoras dentro de un contexto vulnerable, contribuye a las familias sujeto de la investigación en la medida en que se sensibilizó a la sociedad sobre las necesidades y realidades, tanto sociales, económicas y políticas, que estas tienen. Si bien los entes gubernamentales participan en la creación de políticas públicas distritales para esta población, se puede afirmar que no se evidencian prácticas concretas que muestren una garantía real de sus derechos a nivel de salud, vivienda, educación y participación social tal como lo argumenta la Organización de las Naciones Unidas:

Aquellas personas que tengan deficiencias físicas, mentales, intelectuales o sensoriales, al interactuar con diversas barreras, pueden impedir su participación plena y efectiva en la sociedad, en igualdad de condiciones con los demás. (ONU, 2006)

Todos los seres humanos son diferentes y, por lo tanto, son los obstáculos del entorno los que no permiten que las personas participen de todas las actividades y se desarrollen plenamente sin importar su condición. Es necesario hacer partícipes a las personas con discapacidad, a sus cuidadoras y a sus familias, en la construcción y ejecución de las políticas públicas, partiendo de sus necesidades.

Las narrativas, según Flick (2007), permiten al investigador, a través de una pregunta concreta y preguntas generadoras, el acercamiento a un relato que referencia sucesos y acciones que implican el criterio propio de las madres, ya que son las únicas conocedoras de las necesidades, satisfacciones y el manejo de la discapacidad en casa.

Luego de realizar las narrativas, se realizó un análisis por medio de categorías predeterminadas y en directa relación con los objetivos específicos de la investigación, los cuales están dados en términos de prácticas y concepciones del cuidado e incidencia en la calidad de vida de las familias de niños y/o niñas con discapacidad. Durante el análisis 
surgen categorías emergentes de gran relevancia durante las narrativas de las madres y que dan cuenta de algunas situaciones como el miedo y la angustia a "qué pasara con el hijo o hija cuando ellas no estén esde"; dla percepción de las cuidadoras, los niños y niñas con discapacidad difícilmente llegaran a tener una vida "normal". Así mismo, hay un miedo al rechazo y lástima de la sociedad, ya que las madres manifiestan en sus narraciones que las personas aún no están preparadas para compartir y comprender la discapacidad de los niños y niñas, lo que se hace evidente con burlas, rechazos y críticas; y, por último, la frustración por no saber cómo asistir la condición de su hijo o hija con discapacidad.

A partir de los antecedentes encontrados en el análisis de las categorías predeterminadas y emergentes se evidencia que en algunas investigaciones estas temáticas se relacionan, ya que las investigaciones afirman que el cuidado que ejerza la familia de los niños y niñas con discapacidad debe partir del amor, respeto y buen trato, indistintamente del contexto sociocultural en que se desarrollen. Adicionalmente, esta investigación logra, con base en las experiencias de las cuidadoras, comprender cómo las redes de apoyo afectan la calidad de vida tanto del niño y/o niña con discapacidad, como de la cuidadora, debido al impacto que se puede generar en su condición de salud y su situación emocional y económica.

\section{Marco teórico}

\subsection{Narrativa como una construcción de conocimiento con desarrollo epistemológico}

Las narrativas relatadas por las cuidadoras proporcionaron expresiones individuales que nacen de las vivencias concretas de cada sujeto, generadas a partir de una descripción y secuencia de hechos. Se espera que en cada una de ellas se encuentre una verdad y certeza para estudiar la importancia de la construcción del conocimiento y la subjetividad dentro de su realidad.

Desde esta perspectiva, cabe anotar que la narrativa es un acercamiento directo (sujetosujeto) hacia los cambios culturales, sociales, políticos, económicos y religiosos que se encuentran marcados en la sociedad, ya sea para alguien en particular o para una población en general. Para esta investigación la narrativa se construye a través del conocimiento, que surge del reconocimiento integral de acciones como conocer y comprender causas, consecuencias, lugares, motivos, características, factores de cambio y representaciones significativas. De acuerdo con Nussbaum (2005), se considera que las narrativas logran comprender y conocer las distinciones de la vida de cada individuo y de las particularidades que hacen que cada persona sea diferente, en donde se visibilizan las condiciones y los sueños, con el funcionamiento de las posibilidades, y en donde se pueden ver 
las afectaciones interpersonales. De esta manera, cada individuo conoce y comprende su entorno, permitiendo, a través de su propio relato, que la sociedad o alguien en particular conozca su historia. Esto puede ser un intercambio de información en el que los "[...] lectores evalúan esas diferencias, examinando su incidencia en las aspiraciones a una vida plena y satisfactoria" (Nussbaum, 2005, p. 129). De allí se desprende la articulación de lograr que esa narrativa se convierta, para el lector, en un imaginario que le permite tener un acercamiento a los sucesos favorables y desfavorables que afectan la calidad de vida de las familias y de los niños y niñas con discapacidad, con el fin de que la experiencia genere un de reconocimiento de las capacidades, habilidades, destrezas y necesidades de cada familia, para lograr ver el mundo en una dinámica de transformación permanente hacia la sensibilidad y aceptación de la diferencia del otro.

Ahora bien, las narrativas permiten valorar y respetar las diferentes libertades y particularidades del ser humano "[...] por la manera en que se muestre respeto por la individualidad y la intimidad de cada mente humana" (Nussbaum, 2005, p. 140). A partir de dichas narrativas y del reconocimiento que cada familia logra, podrán enfrentar de mejor forma las situaciones de la vida diaria que cada una asume. En esta investigación, el análisis se realizó sin dar ningún tipo juicio o señalamiento sobre las prácticas de cuidado dentro de las familias, en aras de comprenderles como ciudadanos razonables que cultivan su humanidad a partir de los cuidados para vivir mejor en relación con el otro.

Para Nussbaum (2005), los ciudadanos que cultivan la humanidad reconocen al otro en cualquier contexto como una persona integral; sin embargo, para esto se requieren tres habilidades: la primera es la habilidad para un examen crítico de uno mismo y de las propias tradiciones, la cual no acepta las creencia o costumbres de una tradición familiar por el hecho de nacer para ser impuestas; es necesaria la capacidad de una persona de verse a sí misma, capaz de razonar lógicamente y de tomar decisiones de acuerdo a sus juicios e ideales. La segunda es la capacidad de verse a sí mismos no solo como ciudadanos pertenecientes a alguna región o grupo, sino como seres humanos vinculados a otros por lazos de reconocimiento y mutua preocupación; en ella se resalta la necesidad de generar conciencia al comprender que, aunque cada ciudadano es distinto por su crianza y costumbres, las capacidades del otro deben de ser valoradas, para entender los objetivos y necesidades comunes. Y la tercera es imaginación narrativa y hace énfasis en la relación de las dos habilidades anteriores, la imaginación es la capacidad de pensar, de ubicarse en el lugar del otro y llegar a comprender sus necesidades y satisfacciones convirtiéndolas en las suyas propias; es convertirse en un lector inteligente de la historia de otras personas.

En síntesis, estas tres habilidades, propuestas por Nussbaum (2005), se relacionan con las prácticas de cuidado en cuanto la integración de las mismas propende por el bienestar, inicialmente propio, y luego transmitiéndolo a la preocupación por el otro, a la satisfacción de la necesidades, a la comprensión del mundo y de las diferentes realidades, convirtiéndolas, en todos los casos, en las propias. 


\subsection{El cuidado como ética relacional}

La ética es considera como los valores y principios que permiten la práctica de la acción moral, generados de los diversos comportamiento del ser humano, abarcando las normas para la convivencia en cualquiera de los contextos. Por tanto, desde la familias se establecen responsabilidades y se desarrollan actividades cotidianas, ya que al tener un vínculo de parentesco o cercanía se debe asumir el compromiso del cuidado de un ser querido desde sus valores, principios éticos y morales. "Cuando cuidamos, tenemos que hacer uso de la razón para decidir qué hacer y cuál es la mejor manera de hacerlo" (Noddings, 2009, p. 40); es por esto que las familias toman las decisiones, supervisan, apoyan y realizan las actividades de la vida diaria, con todo el compromiso para cubrir las necesidades de quien se encuentra al cuidado de la misma.

Noddings (2009), considera que la relación mutua que ejerce el cuidar y ser cuidados, que se da entre dos personas particulares, permite fortalecer un conocimiento apropiado para que en la vida futura se logren relacionar de una manera plena ante diversas situaciones con otras personas. Por tal motivo, se debe mantener una comunicación directa orientada a la comprensión y a suplir las necesidades con el fin de mejorar la calidad de vida de cada individuo, promoviendo un crecimiento favorable con seguridad y aceptación social.

Esta investigación da a conocer la labor que ejercen las madres en el cuidado de los niños y niñas con discapacidad en su primera infancia, ya que son ellas quienes están atendiendo permanentemente las necesidades de esta población: "[...] la ética del cuidado empieza con el deseo universal de ser cuidado, de establecer una relación positiva" (Noddings, 2009, p. 53). Si bien las familias se dedican a satisfacer dichas necesidades, deben tener en cuenta cuál es la mejor manera de hacerlo, priorizando el desarrollo integral del niño y/o niña con discapacidad, y el desarrollo de su vida personal para mantener un bienestar a nivel familiar y social.

\subsection{La inclusión social desde un enfoque diferencial a partir de las capacidades}

Las capacidades son entendidas, según Nussbaum (2007), como los conocimientos, habilidades y destrezas con el fin proveerse de los recursos necesarios, fundamentado a la necesidad de la igualdad, y en construcción de los principio de la dignidad del ser humano. Existen capacidades buenas y las malas; estas últimas deben ser reprimidas por la justicia, ya que se encargan de no valorar a las personas por su condición, raza o sexo, mientras que las capacidades buenas hablan de una vida digna y humana, basadas en los derechos que cada ser requiere para mejorar sus condiciones básicas, donde se respete la diferencia (Nussbaum, 2007). 
Una forma de lograr esto es a través del enfoque diferencial, entendido, según Baquero (2009), como un enfoque ético que acepta y reconoce las diferencias y capacidades de raza, sexo, etnia, identidad de género, ciclo vital y discapacidad.

Es de resaltar que el enfoque diferencial propone brindar a las personas con discapacidad oportunidades de disfrutar y participar de los diferentes escenarios sociales, económicos, de salud y políticos, ya que "[...] son derechos fundamentales de los ciudadanos, y necesarios para una vida digna y decente" (Nussbaum, 2007, p. 173). Desde este enfoque se ve a la persona con discapacidad como un sujeto de derechos.

Ahora bien, esta concepción es pertinente para esta investigación en la medida en que relaciona el enfoque diferencial con las realidades sociales y familiares de cada contexto, ya que "[...] los enfoques actuales sugieren que la discapacidad tiene unas dimensiones que superan un problema de salud individual y reconoce que se afecta a la persona en relación con su familia, y el contexto político, cultural, social y económico" (Baquero, 2009, p. 2).

En aras de garantizar los derechos de las personas con discapacidad, la sociedad ha avanzado en las formas de atención que se le brinda a esta población: anteriormente se hablaba de institucionalizar a las personas en centros especializados en cuidado y rehabilitación, más tarde llega el proceso de integración basado en la normalización, donde se espera que las personas se adapten al contexto, aprendan con personas en la misma condición, y actualmente se habla de la inclusión social. Según la Organización de las Naciones Unidas para la Educación, la Ciencia y la Cultura -UNESCO- (2006) la inclusión social exige transformaciones profundas y presupone que es la sociedad la que se debe adaptar para atender a las personas con discapacidad y responder a las necesidades de los otros. Este proceso no busca homogenizar sino valorar las diferencias, donde se garantiza la presencia, permanencia y participación de todas y cada una de las personas en los diferentes contextos.

Por lo tanto, la inclusión es un proceso que asegura que todas las personas cuenten con igualdad de oportunidades y recursos para participar en los contextos económicos, sociales, políticos y culturales en óptimas condiciones. Tal como lo expresa Nussbaum (2007), cualquier sociedad decente debe responder a las necesidades de asistencia, educación, respeto, actividad y amistad, y debe garantizar los derechos de las personas con discapacidad encaminados hacia la inclusión social.

\subsection{Calidad de vida y vida digna}

La calidad de vida se podría determinar como el bienestar e igualdad de las personas, y la posibilidad de alcanzar su satisfacción a través de la accesibilidad de los recursos. El acceso a determinados bienes y servicios se encuentra enmarcado por las oportunidades 
que le brinde su entorno social, en beneficio de la disminución de la pobreza. De acuerdo con Nusbaum y Sen (1998), el mercado es el componente principal y "natural" para la distribución de los recursos económicos y el Estado se encuentra en la obligación de articular una política social con el mercado para proveer recursos y servicios necesarios básicos a toda la población y suplir sus necesidades. De esta manera, se dejan atrás las desigualdades para mejorar las condiciones de vida, permitiendo alcanzar el desarrollo humano y garantizar las potencialidades de todo los ciudadanos.

En la sociedad, las personas más pobres carecen de posibilidades, no tienen estudio ni medios para la formación; las oportunidades y las redes en algunos momentos son nulas, no hay empleo, no tienen buenas condiciones de salud y vivienda, y solo logran subsistir por las ayudas estatales. Por tal motivo, las políticas no deben ver al sujeto como un beneficiario pasivo. Al contrario, deben tratar de proveer lo que necesitan sin limitarlos y generando un compromiso de capacitación para que conozcan sus capacidades y obtengan por logros lo que necesitan.

El Estado debe proporcionar el cuidado de la salud y la educación para todos -y la calidad de los servicios debe ser tal que no surja una demanda de hospitales o escuelas privadas- $\mathrm{y}$ debe ser posible tener una buena norma de vivienda independientemente del ingreso y del tamaño de la familia. A los que se cree que estén necesitados se les debe apoyar como algo natural. Se debe, por consiguiente, proporcionar subsidios para los niños y pensiones para todos. (Nussbaum \& Sen, 1996, p. 117)

Es importante tener acceso a servicios que generen posibilidades de formar competencias, como el conocimiento que nos brinda la educación y la salud. De allí la necesidad de que las familias vulnerables cuenten con la accesibilidad para hacer que su vida sea digna y tranquila para vivir en un ambiente sano, y en donde, a través de esos recursos, alcancen su propia libertad, que les permite tomar decisiones y conducir la vida hacia un camino productivo y una participación política, cultural y económica. Sen (1999) establece que el ingreso es tan solo un medio, que no mejora necesariamente las condiciones de vida de la gente, porque no solo basta con tener el medio, sino que debe saber emplearlo, teniendo la libertad de decidir el manejo de las capacidades para sobrevivir y no sucumbir.

Así mismo, la calidad de vida de un núcleo familiar al cuidado de un niño o niña con discapacidad se ve afectado por la falta de ingresos o por la distribución de los mismos, causando que sea difícil suplir las necesidades básicas. Sin embargo, la calidad de vida de un niño o niña con discapacidad no solo está dada a la parte económica; tal como se refieren Schalock y Verdugo (2011), la calidad de vida conlleva a prácticas cotidianas centradas en un contexto social de interacción a partir de servicios y programas, teniendo siempre en cuenta a las familias y a sus hijos e hijas con discapacidad. Estos dos autores presentan 8 dimensiones para una mejor calidad de vida. 


\section{Tabla 1. Dimensiones de la Calidad de Vida}

1. Dimensión de
bienestar emocional

\section{Dimensión de} relaciones personales

Tiene en cuenta los sentimientos como la satisfacción, tanto a nivel personal y vital, el concepto de sí mismo, a partir de los sentimientos de seguridad-inseguridad y de capacidad-incapacidad, así como la ausencia de estrés que contiene aspectos relacionados con la motivación, el humor, el comportamiento, la ansiedad y la depresión.

A partir de la interacción y el mantenimiento de relaciones de cercanía (participar en actividades, tener amigos estables, buena relación con su familia,) y si manifiesta sentirse querido por las personas importantes a partir de contactos sociales positivos y gratificantes.

\section{Dimensión de bienestar material \\ Contempla aspectos de capacidad económica, ahorros y aspectos materiales suficientes que le permitan una vida confortable, saludable y satisfactoria.}

Tiene en cuenta las competencias y habilidades sociales, la utilidad social, la participación en la elaboración del propio Plan Personal de

4. Dimensión de desarrollo personal Aprendizaje (PPA). El aprovechamiento de oportunidades de desarrollo personal y aprendizaje o la posibilidad de integrarse en el mundo laboral con motivación y desarrollo de las competencias personales, la conducta adaptativa y el desarrollo de estrategias de comunicación.

Desde la atención sanitaria (preventiva, general, a domicilio, hospitalaria,

5. Dimensión de bienestar físico etc.); tiene en cuenta los aspectos de dolor y medicación y cómo inciden en su estado de salud y le permiten llevar una actividad normal. El bienestar físico permite desarrollar actividades de la vida diaria desde las capacidades y se ve facilitado con ayudas técnicas, si las necesita.

Se fundamenta en el proyecto de vida personal, en la posibilidad de elegir, de tener opciones. En ella aparecen las metas y valores, las preferencias, objetivos e intereses personales.

6. Dimensión de autodeterminación

Estos aspectos facilitan la toma de decisiones y permiten que la persona tenga la opción de defender ideas y opiniones. La autonomía personal, como derecho fundamental que asiste a cada ser, permite organizar la propia vida y tomar decisiones sobre temas de propia incumbencia.

Se valora si es rechazado o discriminado por los demás. Podemos valorarlo a partir de saber si círculo de amigos es amplio o limitado, y si utiliza entornos de ocio comunitarios. La inclusión puede medirse desde la participación y la accesibilidad que permite romper barreras físicas que dificultan la integración social.

Contempla el derecho a la intimidad y el derecho al respeto medible desde el trato recibido en su entorno. Es importante indagar sobre el grado de conocimiento y disfrute de los derechos propios de ciudadanía.
8. Dimensión de defensa de los derechos

Las dimensiones están dadas para que las prácticas de cuidado incidan en la calidad de vida de las niñas y niñas con discapacidad; estas parten de los principios de la Convención sobre Derechos de las Personas con Discapacidad y buscan brindar un bienestar. 


\subsection{Derechos humanos a partir de la Convención de los Derechos del Niño}

Los derechos humanos construyen un reconocimiento positivo para interpretar la realidad de la infancia a través de la Convención de los Derechos del Niño y, de esta manera, aseguran la protección integral en sus primeros años de vida, delegando al Estado y a la familia la responsabilidad de que los niños disfruten de una vida digna y plena sin distinciones o discriminaciones, logrando la participación de los derechos sociales, culturales y económicos.

La Convención de los Derechos del Niño (2006) articula cuatro fases importantes para los derechos del niño en beneficio de hacerse respetar y cumplir. El primero es el derecho a la supervivencia, en donde prima el derecho a la vida, a la nutrición, a adquirir una seguridad alimentaria y física para abarcar toda la seguridad integral. El segundo es el derecho a la protección, para no permitir que los niños se encuentren en condiciones vulnerables de dependencia o en un estado de abandono o de maltrato; también deben de contar con una identificación, es decir, derecho a un nombre y a una nacionalidad. El tercero es el derecho al desarrollo, dirigido a que los niños cuenten con una familia y proyectado a la participación educativa, cultural y recreativa. Y el cuarto es el derecho a la participación, para desarrollar el despliegue de las libertades a partir de la capacidad de pensar desde su autonomía.

La familia es uno de los agentes que garantiza la protección, contención y cuidado, generando autoestima e identidad: "[...] reconociendo que el niño, para el pleno y armoniosos desarrollo de su personalidad, debe crecer en el seno de la familia, en un ambiente de felicidad, amor y comprensión" (Unicef, 2006, p. 8). Así mismo, es el Estado el que debe proteger y promover el bienestar, tanto de las familias como de las personas, en pro de fortalecer la trasformación de la calidad de vida de cada niño, sancionar a quien atente contra estos derechos, y reparar a quienes han sido vulnerados. En consecuencia, se han tenido cambios significativos con los derechos de los niños, entre los cuales se resalta la equiparación de garantías y oportunidades, permitiendo un compromiso hacia el progreso constante y la prevención de posibles abusos.

Cuando se habla de la atención y supervisión a la primera infancia, también se hace énfasis sobre los niños y niñas con discapacidad, ya que ellos cuentan con los mismos derechos. Ellos, por sus características y particularidades ligadas a la discapacidad, requieren de una mayor protección y seguridad integral, lo que implica que se deben de reconocer dentro de la construcción social, pero dentro de las posibilidades que la misma sociedad brinde. Precisamente, esto implica enriquecer todo proceso potencializando su participación y autoestima, y garantizando los derechos día a día. 


\section{Revisión de literatura}

Para el desarrollo de esta investigación se realizó una recopilación de diferentes fuentes investigativas, seleccionando los puntos fundamentales de acuerdo a sus conceptos a través de un proceso de selección y búsqueda. Este proceso se realizó con el objetivo de conocer qué investigaciones hasta el momento se han realizado en términos de narrativas a la atención del cuidado en la primera infancia con discapacidad y del reconocimiento de la visión de las familias cuidadoras en cuanto a las concepciones, prácticas e incidencia para la calidad de vida.

Para Melo (2011), las diferentes narrativas arrojadas dan cuenta que en las pautas de crianza en la primera infancia es fundamental el ejercicio de prácticas de cuidado y protección, a fin de generar ambientes estables y favorables a un desarrollo emocional, mental y físico apropiado para los niños y niñas, sin generar temor por golpes o malas palabras que limiten el diálogo frecuente. Además de promover que los niños y niñas crezcan en un hogar estable lleno de buenos ejemplos, es importante que, a partir del buen cuidad, se les transmita el respeto hacia los demás y se les genere autoconfianza y buenos valores. En relación con la investigación, se evidencia coherencia con el enfoque epistemológico, en la medida en que el cuidado que ejerza la familia de los niños y niñas con discapacidad independientemente del contexto y de las condiciones sociales en que viva, debe propender en el respeto, el amor y el buen trato.

Marroquín, García y Cachila (2011) presentan la crianza como un proceso para permitir una educación de calidad y relacionado con el cuidado y las condiciones sociales, ya que no es solo en casa en donde se ayuda a fortalecer sus acciones a través del diálogo y orientaciones constantes para el desarrollo de sus relaciones, sino también en las instituciones educativas, que tienen la responsabilidad de la educación para la primera infancia. La metodología que se implementó es una investigación/intervención y su técnica cuenta con un guión, que contiene el objetivo, las preguntas orientadoras, las técnicas e instrumentos. La investigación relaciona las condiciones sociales con el cuidado de la primera infancia, siendo un determinante para la calidad de vida de las personas a través de las narrativas, Se comprendieron las experiencias de familias a partir de la consolidación de redes familiares para reconocer y garantizar el bienestar de niños y niñas.

Para Úbeda (2009), el cuidado de personas dependientes, generalmente, es asumido por las mujeres de las familias, quienes presentan bajos niveles educativos con estudios de primaria incompletos y con dificultades para acceder a oportunidades laborales porque se desempeñan en la actividad de cuidado de manera permanente. Las prácticas de cuidado están relacionadas con actividades de la vida diaria y cuidados de tipo psicosocial. Los cuidadores familiares expresan que el cuidado les provoca problemas físicos, manifestaciones psicológicas, dificultad en la gestión del tiempo, menos relaciones sociales, alteraciones familiares y han visto reducida su economía. El enfoque de la investigación 
es empírico - analítico, y la técnica que se aplica es una encuesta dirigida a 240 cuidadores familiares de personas dependientes en el domicilio. El tema de esta investigación está relacionado con la experiencia del cuidado familiar a niños y niñas con discapacidad. Los hallazgos de la investigación dan cuenta del impacto que tiene el ejercicio del cuidado en las familias, y especialmente en quien tiene la responsabilidad del cuidado porque su condición de salud y su situación emocional y económica se ven afectadas de manera desfavorable.

Cruz (2010) concluye que las madres asumen diversos roles tales como enfermera, profesora, terapeuta, y en ocasiones, dependiendo de su nivel de compromiso y dedicación, pueden jalonar o detener los procesos que llevan sus hijos, pues en muchos casos suelen sobreproteger a su hijo limitando sus capacidades, mientras que en otros los estimulan frecuentemente con el fin de volverlos más funcionales y con mayores competencias para el trabajo con el otro. La metodología que implementa esta investigación es cualitativa con una técnica de entrevistas. La investigación indaga por la calidad de vida de las madres cuidadoras de hijos con síndrome de Down.

Para Opina (2007), la discapacidad, la familia y la sociedad necesitan construir redes sociales para obtener una calidad de vida adecuada, porque los padres de una persona con discapacidad tienden a victimizarse y a no enfrentar la realidad que los acoge viendo su situación como una catástrofe para ellos y para su contexto familiar. Esta investigación, en su metodología, desarrolla una "triada" sociedad - familia - discapacidad, con una técnica de formación psicopedagógica, teórico - técnica adecuada. El artículo es el resultado de una investigación que indaga por la incidencia de las redes sociales en la calidad de vida de las familias de personas con discapacidad.

Finalmente, para Córdoba, Gómez y Verdugo (2008), el cuidado de una persona con discapacidad generalmente es asumido en la familia por la madre, quien asume los roles de cuidado y crianza de los hijos, mientras que el padre se encarga en gran medida de proveer las necesidades básicas de la familia, tales como la vivienda, la alimentación y el vestuario. La investigación presenta la situación de los cuidadores familiares de personas con discapacidad y busca identificar la calidad de vida de quien asume de manera permanente el rol de cuidador y las afectaciones que tiene esta actividad en su estado de salud física y emocional, y en su economía.

\section{Metodología}

La investigación se basa en un enfoque cualitativo histórico hermenéutico que comprende la "[...] relevancia específica para el estudio de las relaciones sociales, debido al hecho de la pluralización de los mundos reales" (Flick, 2007, p. 15) y busca la comprensión e interpretación de contenidos racionales y reales. 
El diseño metodológico se emplea con el fin de buscar una articulación entre el enfoque hermenéutico y la interpretación de lo que cada madre narra en la entrevista, en relación con las concepciones y las prácticas del cuidado de los niños y niñas con discapacidad en sus primeros años de vida, en la localidad de San Cristóbal.

Este diseño de investigación fue flexible y permitió indagar situaciones y hechos de la vida de los seres humanos, interpretando el significado de quién da la información por medio de elementos como: relatos, entrevistas y narrativas, que permiten una construcción de una realidad social. De acuerdo a Coffey y Atkinson (2004), es de gran importancia la perspectiva personal de las familias, ya que son las únicas conocedoras de sus vivencias, y esto permitirá tener un acercamiento e interacción directa con la población, para comprender el contexto que rodea la familia.

\subsection{Población}

Siguiendo el diseño histórico hermenéutico en que se basa la investigación, se determina que la población sujeto de estudio son cinco familias madres cuidadoras, que se codifican como Entrevista Cuidadora 1, 2, 3, 4 y 5, lo que permite reconocer detalles de cada una de ellas. De esta manera, se permite comprender el contexto de cada familia y, así, su incidencia sobre cómo se concibe la discapacidad del niño o niña dentro de ella, ya que es diferente dentro de cada una. Aunque se reconoce que hay diferencias en cada situación a nivel de discapacidad que tiene cada niño o niña, esta investigación no pretende comparar las diferentes condiciones. Esta investigación sí espera indagar si la situación de discapacidad es influyente para la calidad de vida de cada familia.

Para facilitar el entendimiento de cada una de las entrevistas, se elaboró un genograma que permite que el lector comprenda con facilidad algunos aspectos de la dinámica familiar de las cuidadoras. Para la lectura de las mismas, a continuación se presentan las convenciones necesarias:

Tabla 2. Convenciones para la lectura de genogramas

Niña con discapacidad

EC1 Cuidadora Cuidador

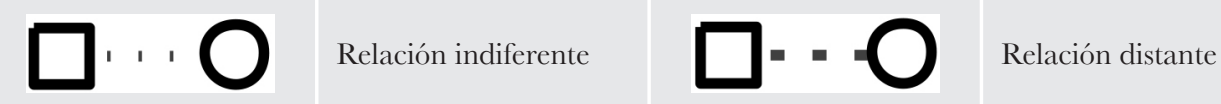


$\square::=0$

Relación discordia/ abandono

Relación permisiva

Separación de hecho
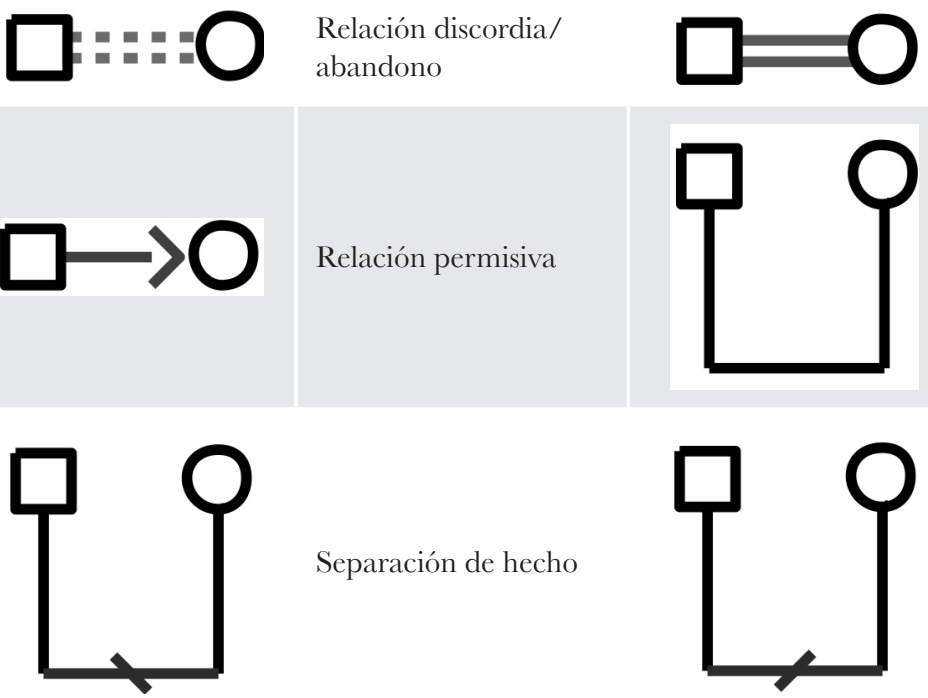

Relación permisiva
Relación cercana

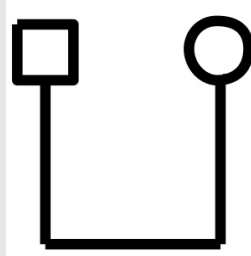

Matrimonio

Separación legal

Relacion cercana
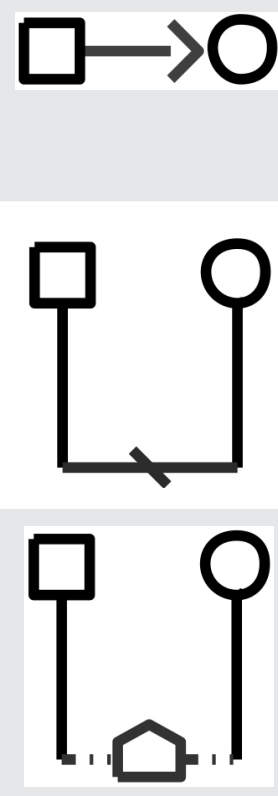

Convivencia

Fuente: elaboración propia.

\subsection{Entrevista Cuidadora $1\left(\mathrm{EC}_{1}\right)$}

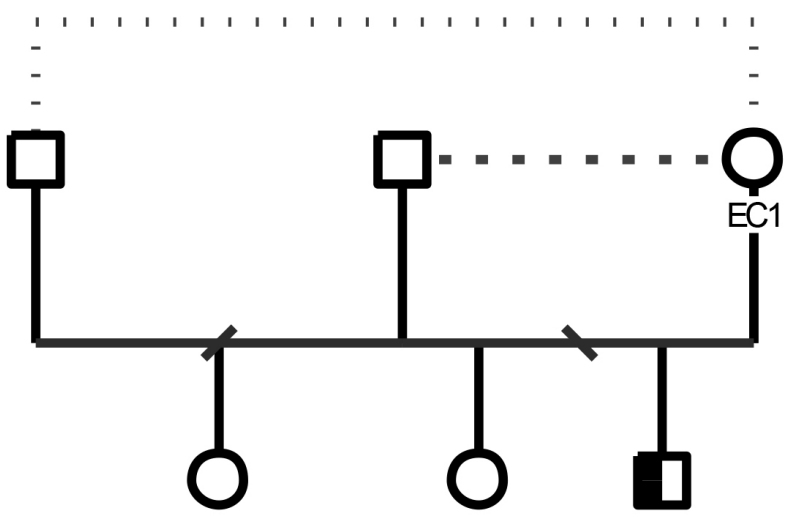

Familia monoparental, compuesta por la madre y tres hijos, dos de ellas mujeres y un hombre, los tres menores de edad. La madre es jefe de hogar, sin trabajo actualmente. 
Los integrantes de la familias satisfacen sus necesidades diarias con la ayuda que los vecinos le brindan, aportando comida, ropa usada y les colaboran con algunas necesidades diarias, y en ocasiones con un trabajo que ella desarrolla esporádicamente lavando o planchando ropa a personas conocidas. La madre no puede adquirir un trabajo formal porque debe estar al cuidado de su hijo, quien por su patología (síndrome de West) convulsiona con frecuencia. Las dos niñas se encuentran en el colegio en primaria y el niño de cuatro años de edad se encuentra en un jardín infantil de la localidad de San Cristóbal.

El niño fue diagnosticado a los seis meses de edad con el síndrome de West o también llamado espasmo masivo infantil. Este síndrome, según Moncayo (2006), es uno de los síndromes epilépticos más severos; se caracteriza por un grupo de tres patologías: una encefalopatía epiléptica más frecuente en los primeros años de vida, evidenciada por espasmos masivos, con una duración de tres segundos máximo y se presenta con contracciones musculares en flexión o extensión de miembros superiores e inferiores y arqueo de espalda, de una manera brusca por los choques eléctricos, haciéndose repetitiva en intervalos de tiempo. La segunda es un retraso en el desarrollo psicomotor: hay pérdida de habilidades motoras y anormalidades neurológicas a causa de las convulsiones ya que estas afectan su procesos. Y la tercera es la hipsarritmia clásica que se evidencia con el enlentecimiento de las actividades eléctricas del cerebro.

\subsection{Entrevista Cuidadora $2\left(\mathrm{EC}_{2}\right)$}

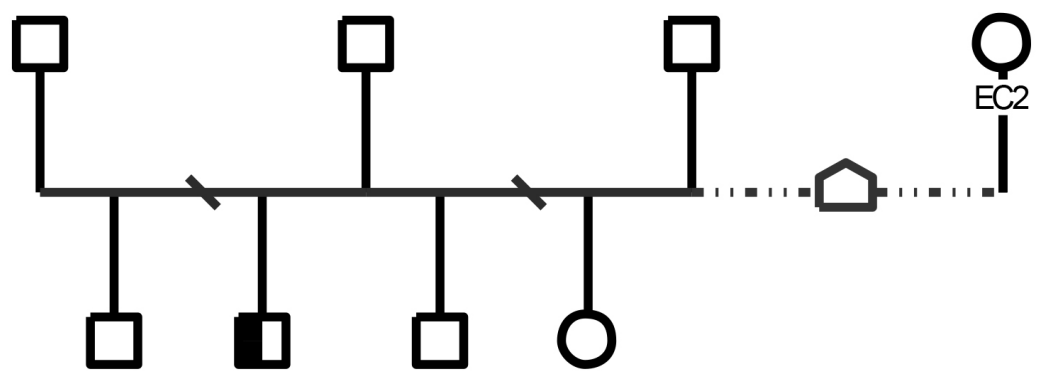

Familia recompuesta por padrastro, madre y cuatro hijos, tres de ellos hombres y una mujer, todos menores de edad. El padrastro es quien lleva el sustento económico a casa, la madre es la cuidadora de los hijos, la niña se encuentra estudiando y los tres niños están en el jardín infantil. Uno de los niños tiene cinco años de edad y a los tres años fue perdiendo sus habilidades motrices, a causa de una enfermedad degenerativa aun no diagnosticada; por ahora se dice que es una parálisis cerebral.

Esta discapacidad, para López (2009), hace parte de una parálisis cerebral espástica que afecta los miembros inferiores. Se caracteriza por mantener las piernas juntas y giradas hacia adentro y los pies en puntas; no en todos los casos hay compromiso cognitivo. Generalmente, la afectación es a nivel motor. 


\subsection{Entrevista Cuidadora $3\left(\mathrm{EC}_{3}\right)$}

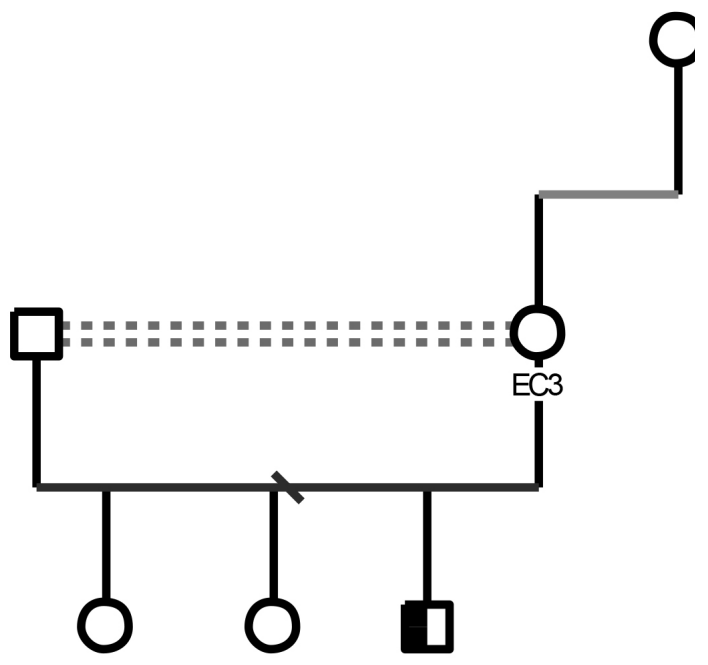

Familia monoparental, compuesta por la madre, dos hijas mayores de edad y un hijo menor de edad; la madre es cabeza de familia, sin trabajo actualmente, las dos hijas trabajan y son quienes llevan el sustento económico a la casa. La madre aporta lo que el padre mensualmente le suministra al niño, quien tiene cinco años de edad y se encuentra en un jardín infantil.

El niño fue diagnosticado, al año de edad, con agenesia de cuerpo calloso. El Centro de Referencia Perinatal Oriente -CERPO- (2003) afirma que esta alteración es la ausencia de las fibras nerviosas que conectan los dos hemisferios cerebrales, llamado cuerpo calloso, el cual se encarga de trasmitir la información sensorial, de la memoria y discriminatoria de un lado a otro. Con frecuencia, esta alteración genera retraso psicomotor, discapacidad intelectual y epilepsia.

\subsection{Entrevista Cuidadora $4\left(\mathrm{EC}_{4}\right)$}

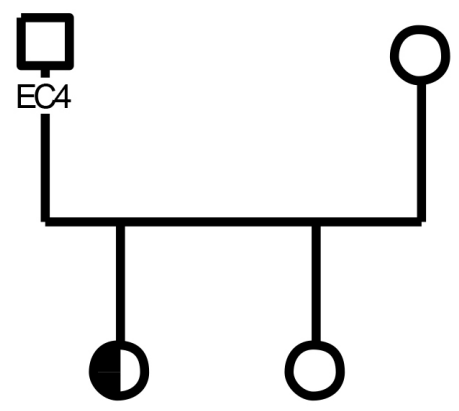


Familia nuclear, compuesta por padre, madre y dos hijas, una de tres años y la otra de cinco años de edad. Esta familia se ubica en estrato uno y no tienen ninguna ayuda económica por parte del Estado, solo cuentan con la ayuda gratuita del jardín infantil para las niñas. El padre es el encargado de llevar el sustento económico a casa; sin embargo, actualmente se encuentra en busca de trabajo, ya que el anterior lo perdió hace poco tiempo. Por lo tanto, mientras su esposo se ubica laboralmente, la madre se ve en la obligación de trabajar algunos días haciendo aseo en un jardín, y los días que no está haciendo aseo le ayuda a su hermana a realizar collares artesanales. En este momento, el padre es el encargado del cuidado de las dos niñas, pero se observa en él cierta preferencia por su hija mayor, quien al nacer fue diagnosticada con microcefalia.

La microcefalia es concebida por Baxter (2009) como la pequeñez anormal de la cabeza o bajo volumen en el perímetro cefálico en comparación con la mayoría de los niños de la misma edad. Se caracteriza por que en la mayoría de los casos trae consigo el retraso del desarrollo, dificultades de aprendizaje o discapacidad intelectual. Las principales causas de esta discapacidad son genéticos o ambientales, por consumo de sustancias psicoactivas, licor o tabaquismo.

\subsection{Entrevista Cuidadora $5\left(\mathrm{EC}_{5}\right)$}

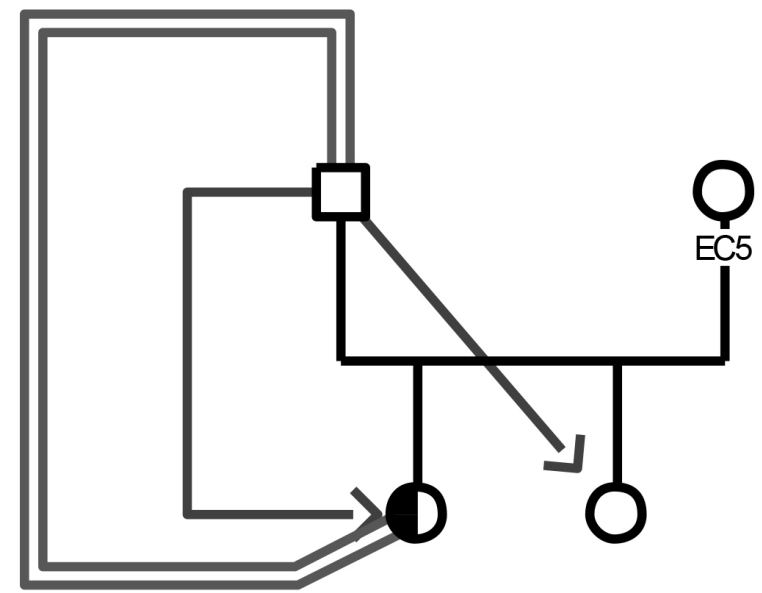

Familia nuclear, compuesta por padre, madre y dos hijas, una de cuatro años y la otra de cinco años de edad; el padre es quien trabaja para llevar el sustento al hogar, recibe mensualmente un salario mínimo vigente, y la familia no recibe ninguna ayuda económica por parte del Estado. La madre no puede desempeñarse laboralmente ya que se encuentra al cuidado de sus hijas. El padre no ejerce autoridad ni normas sobre los comportamientos de ellas, siendo demasiado permisivo, especialmente con su hija mayor 
debido a que siente temor por no saber cómo tratar la condición de la niña, quien está diagnosticada con autismo.

Amoni (2011) argumenta que el autismo es un trastorno generalizado del desarrollo permanente, en el cual se manifiestan cambios de conducta repentinos, repetitivos y disruptivos. Además, se caracteriza por el desinterés de iniciar y mantener interacciones sociales, el aislamiento o estereotipias (movimientos repetitivos inconscientes) y la dificultad a nivel de comunicación y/o lenguaje para expresar gustos, necesidades o sentimientos. Cuando personas con autismo adquieren lenguaje oral, generalmente, en sus producciones se evidencia la ecolalia (la repetición constante de los fonemas, palabras o frases escuchadas con anterioridad) como forma de comunicación.

\section{Técnicas de recolección de datos}

La recolección de datos se realizó en dos fases: (i) Una entrevista realizada para la recolección de narrativas y (ii) el análisis de categorías de las narrativas de manera cualitativa.

Las narrativas proporcionan datos específicos útiles para el objetivo del investigador, ya que su contenido y estructura detallan historias y secuencias, lo que aporta al conocimiento y análisis de la realidad social y familiar.

Si ha de lograrse una narración que sea relevante para la pregunta de investigación, la pregunta generadora de narración se formulará de manera amplia, pero al mismo tiempo lo suficientemente específica para que el dominio de experiencia interesante se adopte como tema central. El interés se puede referir a la historia de la vida del informe en general [...] (Flick, 2007, p. 111)

Por lo tanto, esta investigación se centró en permitir la recolección de datos que amplían el conocimiento de un medio social, su sentir, sus acontecimientos, conocimientos, experiencias, puntos de vista y demás criterios que le ayudaran al investigador a realizar una interpretación, comprensión, construcción y reflexión de la realidad social.

En aras de recolectar dicha información se realizó una entrevista "[...] que se centr[a] en la escucha activa, es decir, señal[a] interés sin intervención, y en cómo mantener la relación con el entrevistado" (Flick, 2007, p. 116). Estas entrevistas deben tener en cuenta "[...] la pregunta de investigación concreta y el grupo objetivo específico cuyas narraciones se buscan" (Flick, 2007, p. 116). A lo largo de esta investigación, se basó el proceso en la metodología propuesta por Flick (2007), quien sugiere tres elementos necesarios para desarrollar una investigación objetiva: (i) la orientación primaria, la cual pretende que la familia tenga la libertad necesaria al relatar su historia por varias horas; (ii) las intervenciones concretas, donde se pueden plantear preguntas solo al finalizar la intervención de las familias de manera directa; y (iii) las preguntas generadoras, las cuales sirven para estimular la producción de una narración y para relacionarlas con la incidencia en la calidad de vida de las familias (Flick, 2007). 
Teniendo en cuenta los elementos descritos anteriormente y los objetivos específicos de esta investigación, se plantearon las siguientes preguntas básicas para iniciar, mantener y cerrar la entrevista narrativa:

1. Pregunta de introducción para cada familia:

- ¿Cuénteme cómo ha sido el proceso del cuidado de su hijo/a con discapacidad en el contexto familiar?

2. Preguntas concretas al momento de culminar la narración libre:

- ¿Qué fortalezas reconoce en el proceso del cuidado de su hijo?

- ¿Qué dificultades reconoce en el proceso del cuidado de su hijo?

- ¿Cuáles considera usted que son las necesidades principales de su familia?

3. Preguntas generadoras para especificar la concepción, la práctica del cuidado y la incidencia en la calidad de vida, a partir del relato:

- ¿Cuáles son las concepciones a nivel familiar en el cuidado de su hijo?

- ¿Cómo son las prácticas que realiza en el cuidado de su hijo?

- ¿Cómo considera usted que la discapacidad de su hijo incide en la calidad de vida de su familia?

A partir de dichas narrativas se realizó el análisis por categorías. Este permitirá descubrir, con detalles cotidianos, las vivencias, las estrategias y necesidades que representa el tener un niño o niña con discapacidad dentro de su contexto familiar. Estas narrativas permitieron construir minuciosamente la dinámica que realiza cada familia en cuanto a la práctica y las concepciones que tienen dentro de ellas, en aras de conocer la incidencia en su calidad de vida.

\section{Discusión y resultados}

\subsection{Categorías predeterminadas}

\section{Sobre la concepción del cuidado}

Luego de interpretar las narrativas elaboradas por las cinco madres de los niños y niñas con discapacidad de la localidad de San Cristóbal, se obtuvieron algunos hallazgos sobre la concepción que ellas tienen sobre las prácticas de cuidado que desarrollan a diario al interior de sus hogares. Los hallazgos se estudian "[...] reconociendo que el niño, para el pleno y armoniosos desarrollo de su personalidad, debe crecer en el seno 
de la familia, en un ambiente de felicidad, amor y comprensión" (Unicef, 2006). Para las familias de los niños y niñas con discapacidad la concepción del cuidado es sinónimo de protección, compañía, amor, atención, aceptación, comprensión y dedicación de tiempo. Sin embargo, se evidencia que las cuidadoras principales conciben en sus respuestas sobre el cuidado que este implica sobreprotección, y ellas supeditan su ser o su identidad a la del niño o niña. Esto se observa en el hecho de que ninguna menciona en su descripción de cuidado la autonomía o interdependencia, palabras que denominan o proyectan una visión ampliada de que el cuidado no debe ser solo amor, protección, seguridad, sino permitir el desarrollo individual y guiar la formación de personas con derecho a desarrollar su personalidad, la cual se gesta desde la primera infancia.

"para mí, cuidar a nuestros hijos es poder brindar ese apoyo económico y psicológico para acá, para la casa, dedicándoles tiempo con amor y dedicación” $\left(\mathrm{EC}_{2}\right)$

Entre las expresiones de amor y orientación que se debe brindar a los niños en discapacidad, está el saber corregir y comprender, para que en el momento de manifestar alguna situación que él no deba hacer, lo entienda y no vaya a sentir ningún tipo de contrariedad.

"Me gusta estar con él todo el tiempo, ayudarlo, consentirlo, protegerlo, acompañarlo y comprenderlo, sé que es una personita que necesita que lo entiendan, no que lo regañen, ni lo rechacen. Yo le ayudo en lo que más puedo" $\left(\mathrm{EG}_{3}\right)$

La concepción de cuidado para las cuidadoras está ligada a la satisfacción de las necesidades de sus hijos e hijas, siempre realizándolo con el amor que genera el vínculo afectivo que tienen con ellos. Este cuidado se caracteriza por la dedicación y el afecto que desean transmitir al mantenerlos en buen estado de salud, suministrarles la correcta alimentación, vestirlos cómodamente, mantener la higiene y, en general, conservar en buen estado la vivienda e incluso ofrecerles espacios de recreación. Esta postura es evidente en el siguiente relato:

"Soy capaz de cuidar a mi hija, de alimentarla, vestirla, para hacer que ella cada día se vea bien y se sienta bien" $\left(\mathrm{EC}_{4}\right)$

Ahora bien, dentro de la concepción de cuidado se percibe que lo económico sobre sale a lo emocional, aunque este es sine qua non en la calidad de vida; sin embargo, no hay una relación de equilibrio entre el cuidado emocional y el cuidado económico, lo que tendería a condicionar el trato del núcleo familiar en general hacia el niño o la niña con discapacidad.

"Para una buena alimentación, un buen vestir y una buena recreación, si yo tuviera un trabajo, esas tres se las daría perfectamente a mi hijo, pero como no las tengo, entonces no las puedo cubrir, ahora, ahora si no lo cuido yo quién lo cuida" $\left(\mathrm{EG}_{2}\right)$ 
En estas concepciones del concepto de cuidado, las cuidadoras afirman además que requieren de un apoyo a nivel institucional que les permita a sus hijos tener una rehabilitación integral, ya que no cuentan con un sistema de salud integral que les garantice los procesos que requiere el niño o niña con discapacidad para superar sus dificultades. De acuerdo a Baquero (2013, p. 156), "[...] la exclusión social se manifiesta en la falta de oportunidades, en acceso a la salud, la rehabilitación y la educación". A diario, estas familias se esmeran por incluir a sus hijos en diferentes escenarios sociales. Sin embargo, se percibe que algunas cuidadoras conciben la institucionalización como la salida a su problemática de permanecer con el cuidado de sus hijos o hijas, sin tener en cuenta que caen en el asistencialismo, contradictorio a los principios de la concepción de cuidado que cada una de ella ha mencionado.

"Un jardín, un colegio, una institución, una fundación en la cual a ellos lo trataran de siete de la mañana a seis de la tarde, donde tengan enfermera, donde tengan terapeutas, donde les den el complemento, donde les hagan todas las terapia que ellos requieren" $\left(\mathrm{EC}_{2}\right)$

"Una rehabilitación integral para la niña. Con eso nos ayudaría al manejo de sus actividades y no sería tan difícil cuidarla" $\left(\mathrm{EC}_{5}\right)$

Sin duda, los procesos de rehabilitación de las personas con discapacidad marcan una diferencia en su calidad de vida, en la medida en que fortalecen las habilidades de estas personas, disminuyen sus dificultades y afianzan sus procesos diarios. Esto es reconocido por los cuidadores de los niños y niñas con discapacidad; de ahí que se interesen y preocupen por que estas terapias sean brindadas en forma idónea a sus hijos.

Ahora bien, las cuidadoras de los niños y niñas con discapacidad consideran que, en el cuidado de ellos, las responsabilidades deben ser compartidas, ya que el compromiso no debe ser asumido solamente por la madre del niño. Para Nussbaum (2007, p. 114), “[ ...] la asistencia ordinaria a los niños todavía recae de forma desproporcionada sobre las mujeres, pues las mujeres están mucho más dispuestas a asumir trabajos a tiempo parcial y las limitaciones profesionales que ello supone". Si bien es cierto que el cuidado depende mucho de la actitud y disposición del cuidador o cuidadora, no puede limitarse a que las satisfacciones de las necesidades básicas, la comprensión del seguimiento de normas y límites, y las demás dinámicas de cuidado recaigan solamente en un miembro de la familia. Sin embargo, se percibe que los patrones de crianza discrepan, lo cual genera que recaigan en excusas de evasión ante el cuidado de los niños y niñas con discapacidad:

"El cuidado es una responsabilidad de dos padres no solo de uno" $\left(\mathrm{EG}_{3}\right)$

"En el cuidado de mi hijo es que solo yo como madre lo entiendo, entiendo sus necesidades y alegrías, nadie más lo entiende por su condición de brusquedad" $\left(\mathrm{EG}_{3}\right)$

"Nosotros como padres pudiéramos dialogar, comunicarnos y llegar a acuerdos sobre los cuidados, para que el padre no le permita todo lo que ella quiera" $\left(\mathrm{EG}_{5}\right)$ 
En síntesis, se observa en el análisis de las narrativas que los cuidadores de los niños y niñas con discapacidad suelen, en sus concepciones de cuidado, percibir que se refleja con un buen aseo personal, buena accesibilidad a la salud y, en general, la adquisición de habilidades básicas. Así mismo, dejan ver que para las familias el cuidado permanente de sus niños, la satisfacción de sus necesidades y el goce de sus alegrías es una tarea netamente de la familia; "[...] el cuidador y el receptor del cuidado establecen una relación mutuamente satisfactoria [...]" (Noddings, 2009, p. 42) que solo es comprendida por el cuidador o cuidadora, ya que, para ellos, nadie entiende ni se compromete con este proceso de cuidado. Ellos reconocen que es un proceso muy importante para el desarrollo integral de los niños o niñas, el cual está relacionado con la posibilidad de adquirir la rehabilitación integral.

\subsection{Prácticas del cuidado para optimizar la calidad de vida}

En las narrativas se observó que en la práctica del cuidado es la madre del niño o niña con discapacidad quien asume el cuidado del mismo, pues si bien "[...] en casi todas las culturas, las mujeres, al parecer, desarrollan la capacidad de cuidado más que los hombres" (Noddings, 2009, p. 50), en este caso es la madre quien se compromete con el cuidado de sus hijos o hijas. Ahora bien, cabe anotar que dentro de las culturas latinoamericanas el patriarcado es el que prima en la dinámica familiar, pero un patriarcado entendido desde la concepción machista que condiciona y determina que el cuidado del hogar debe permanecer a cargo de la madre porque el padre es quién provee de sustento económico a la familia. En otras dinámicas, los padres, por múltiples razones, optan por relegar totalmente la carga a las cuidadoras dejándolas solas a cargo del niño o la niña con discapacidad, lo cual no justifica los roles que debe asumir la cuidadora en el núcleo familiar y en el cuidado del niño o la niña.

"Dejé de ser mujer para solo ser madre cuidadora las 24 horas de un niño a quien amo" $\left(\mathrm{EC}_{3}\right)$

"A mí es la que me toca toda la carga del cuidado de las niñas porque mi esposo trabaja, al menos gracias a Dios el tiene un trabajo estable y yo me puedo dedicar a la niña, eso es bueno" $\left(\mathrm{EG}_{5}\right)$

Las madres cuidadoras son conscientes de que si bien en algunos casos cuentan con redes de apoyo, la responsabilidad en la crianza de los niños y niñas con discapacidad y el cuidado en términos de salud, educación y rehabilitación es de ellas.

El sistema de salud que usan los niños y niñas requiere de un tiempo, desgaste y trabajo permanente por parte de los cuidadores o cuidadoras; ellos deben llevar a cabo procesos legales como el derecho de petición o la tutela para exigir que se les garantice el derecho que tienen a nivel de rehabilitación, medicamentos, redes de apoyo, aditamentos, ayudas técnicas y/o consultas con diferentes profesionales especialistas de la 
salud. Además, "[...] muchas veces no reciben la asistencia médica y la terapia que necesitan" (Nussbaum, 2007, p. 202). Las cuidadoras asumen un rol implícito, el cual va dirigido a ser agentes multiplicadoras del proceso de sus hijos por cuanto deben buscar información y asesorías que les permitan optimizar el proceso de rehabilitación y de reconocimiento como sujetos de derechos, los cuales son inherentes a las acciones en la calidad de vida. Además, informan a las demás cuidadoras la forma de obtener lo que en materia de salud les corresponde.

"Me toca luchar también con tutelas, tengo en tutelado, me tocó en tutelar a Humana Vivir por el medicamento porque no me lo querían dar ni nada de eso, se metió una tutela, me tocó meter otra tutela para lo de la silla de ruedas" $\left(\mathrm{EG}_{1}\right)$

"Yo comencé a luchar por la vida de él, desde ese instante, desde los seis meses, hasta el día de hoy hemos sacado mi hijo adelante es por medio mío, por la uñas que yo he sacado por la tutelas, por los desacatos, por hablar aquí, hablar con todo el mundo, investigar, preguntar, con muchas personas he averiguado para poder sacar a Santiago adelante de su enfermedad de su síndrome de West que es tan severo" $\left(\mathrm{EC}_{2}\right)$

Debido al difícil acceso al sistema de salud y educación de los niños y niñas con discapacidad, sus cuidadores y cuidadoras se convierten en terapeutas, médicos, abogados, pedagogos, entre otros, con el fin de optimizar su calidad de vida.

"Mis hijos no me lo rechazan, me lo quieren mucho. La niña mayor me colabora bastante juega con él, ella me colabora haciéndole masajes al niño parece ella una viejita con el niño. Esa es la realidad y nosotros permanecemos mucho en familia" $\left(\mathrm{EC}_{1}\right)$

"Le hago masajes en las piernas heee, también le hago movimiento en la cara. A veces le compro helados le echo en lo cachetes para que movilice su lengüita" $\left(\mathrm{EG}_{1}\right)$

"Le doy la comidita sentadito. Ya los líquidos no tengo que dárselos con jeringa sino que ya es con una cuchara. Las comidas ya él mastica solo, ya mueve la mandíbula solito por los masajes que le hago y así que yo lo pongo a caminar esas son las ayudas que yo le ayudo en la casa" $\left(\mathrm{EG}_{1}\right)$

"El lograr avances favorables en mi hijo por mi empeño, porque yo sin saber cómo tratar a una persona con discapacidad aprendí que con todo el amor del mundo pude llenar a mi hijo de grandes cosas y hacer que él adquiera mas habilidades para su vida diaria" $\left(\mathrm{EG}_{3}\right)$

Para las cuidadoras, el mínimo avance de un niño o niña con discapacidad resulta muy significativo en la medida en que comprenden que este proceso de desarrollo es lento y que para el niño cualquier habilidad adquirida es resultado de la estimulación que ellos brindan. Como ellos mismos afirman, los niños o niñas con discapacidad serán a futuro lo que ellos hagan en el presente. Desde su práctica son conscientes de que, tal como argumenta Nussbaum (2007), el desarrollo de capacidades es un derecho fundamental para las personas con discapacidad, siendo indispensable para una vida digna. Por esta 
razón, se esmeran a diario para que los niños y niñas con discapacidad adquieran habilidades y capacidades.

"En el ámbito familiar ya mis hijas lo cuidan. O sea, nosotros tenemos un amor por él, mejor dicho es especial para él. Él es nuestros ojos, todos tenemos que vivir y yo les he enseñado a mis hijas a que tiene que cuidarlo" $\left(\mathrm{EG}_{2}\right)$

"Las prácticas que tengo yo son respecto, hee el afecto, el amor, el cariño que él sienta ese amor, que uno lo ama, tanto los hermanos como yo como madre, como el papá, como las que..., como los tíos, los abuelos. Ese es el afecto" $\left(\mathrm{EC}_{2}\right)$

"Yo al niño siempre lo mantengo muy limpiecito, ante todo su aseo personal, él no sabe bañarse pero yo lo baño y lo cambio todos los días, le doy su desayuno, él come muy bien pero toca paladearlo, él mastica y come bien pero le da pereza comer solo, toca cucharearle siempre, porque o sino no come y a mí eso sí me preocupa entonces yo lo paladeo" $\left(\mathrm{EG}_{3}\right)$

"La niña convulsiona y toca correr con ella y dura un día en cuidados intensivos y lo peor es que todo lo aprendido lo retrocede hasta el control de esfinteres, la niña va sola al baño es independiente en eso, pero convulsiona y se pierde todo ese proceso y toca volver a enseñarle teniendo en cuenta que para que aprenda un hábito es difícil y toma su tiempo, con la niña siempre hay que estar empezando procesos" $\left(\mathrm{EC}_{4}\right)$

Las prácticas diarias de cuidado están dadas en términos de atención, amor, afecto, dedicación, entrega y esfuerzo, ya que el vínculo entre madre e hijo hace que estos aspectos se manejen de manera afectiva en aras de mantener y mejorar la calidad de vida de la persona con discapacidad y la de toda la familia.

"Sabemos que con cariño y sabiéndole decir las cosas ella aprende" $\left(\mathrm{EC}_{4}\right)$

Con el fin de que cada día el niño o niña con discapacidad tenga una mejor calidad de vida, las madres se esfuerzan por satisfacer sus necesidades básicas, generando sistemas de comunicación que les permitan saber qué requiere el niño en el momento y/o situación precisa. Son ellas quienes comprenden estas técnicas de comunicación, cuando no son tan marcadas y/o significativas. Esta comprensión se logra por la convivencia diaria.

"A él todo toca paladearle, tener paciencia, ser rutinarios" $\left(\mathrm{EC}_{3}\right)$

"Todo lo que se le enseña es por rutina. Tengo la paciencia suficiente para hacerlo, igual solo se le enseña una sola cosa para que no sature su mente de información y se confunda, los avances son lentos porque hasta que no aprenda algo no se le enseña otra cosa. Evelyn, con el papá y conmigo para estar mirándola toda la noche, duerme en la mitad de los dos, nos gusta protegerla mucho, se le está enseñando a que sea más independiente, pero solo las cosas de aseo personal, no para que esté sola, todavía eso no" $\left(\mathrm{EC}_{4}\right)$

"Soy muy paciente para cuidarla, yo la quiero mucho por eso le hago todo, la baño todos los días porque me gusta que esté limpia" $\left(\mathrm{EG}_{5}\right)$ 
Durante las narrativas, las madres comentan que en algunos casos ciertas personas les han enseñado cómo cuidar, corregir, enseñar, educar y criar a sus hijos; en otros han sido conocimientos empíricos que han ido descubriendo y aprendiendo desde la práctica diaria. Como argumenta Nussbaum (2007), la sociedad debe responder a las necesidades de asistencia, educación, respeto, actividad y amistad de los niños y niñas con discapacidad. Desde este punto de vista la familia aprende cómo cuidarlos y hacerlos partícipes de los diferentes escenarios sociales.

\subsection{Incidencia de las prácticas del cuidado en la calidad de vida de las familias}

Durante los análisis realizados a las narrativas se observa en las familias de los niños y niñas con discapacidad que su afecto y dedicación a la hora de realizar las prácticas del cuidado van más allá de pensar cómo este afecta la calidad de vida de los demás miembros de la familia. Es decir, la cuidadora sacrifica su bienestar y, en general, el de su familia por brindarle al niño una estabilidad emocional, afectiva e integral. Si bien son conscientes de que en ocasiones el niño o niña absorbe mucho tiempo, se entregan en el cuidado casi las 24 horas del día.

"El cuidado ha sido un poco bastante duro con el niño, y eso porque en el cuidado tiene uno que estar las 24 horas con el niño, y ese cuidado depende mejor dicho que uno no puede trabajar" $\left(\mathrm{EG}_{1}\right)$

"Que si tengo que ir a la tienda me lo tengo que llevar, que si tengo que ir así sea al baño para allá me lo tengo que llevar" $\left(\mathrm{EC}_{1}\right)$

"El cuidado de mi hijo en el contexto familiar ha sido algo complejo, muy complicado, dificil para toda la familia" $\left(\mathrm{EC}_{3}\right)$

"Dedicarle casi 18 horas al día constantemente sin quitarle los ojos de encima, y que nadie le ayude a uno, peor" $\left(\mathrm{EC}_{5}\right)$

"Como cuidadora hasta se olvida que uno necesita de tranquilidad, yo no tengo tiempo para mí” $\left(\mathrm{EC}_{5}\right)$

Para las familias de los niños y niñas con discapacidad, las prácticas del cuidado son muy difíciles en la medida en que las relaciones familiares se afectan; incluso se generan rechazos o descuidos entre las parejas, los hijos y los demás miembros de las familias. Debido a que el cuidado requiere de una disponibilidad de tiempo grande, se presentan dificultades cuando se descuidan a otras personas o situaciones propias de las dinámicas familiares. Teniendo en cuenta esta situación, Nussbaum afirma que, efectivamente, el hecho de que la discapacidad requiera una asistencia permanente afecta las prácticas de toda la familia. 
"Si se le dedica mucho tiempo se descuida los otros niños. Él necesita que uno esté encima de él, pendiente de él. Eso es lo duro" $\left(\mathrm{EC}_{1}\right)$

"Tener tres hijos prácticamente de la misma edad es muy duro, porque si le pone cuidado a uno descuida a los dos, y si le pone cuidado a los dos descuida al más importante, y si llega a descuidar al más importante, ahí sí Raimundo y todo el mundo, ahí sí conocen fiscalía, ahí sí viene Bienestar Familiar, ahí sí viene integración social, ahí si todo el mundo reconoce a la persona con dificultad. La reconoce inmediatamente" $\left(\mathrm{EC}_{2}\right)$

"Todo el núcleo familiar tiene que cohibirse de salir por una sola persona, por una sola, porque yo no puedo exponer la vida de mi hijo, la comodidad de mi hijo, por las otras dos niñas, entonces toca cohibir a las otras dos niñas por uno solo" $\left(\mathrm{EC}_{2}\right)$

"El poder salir, el poder dormir tranquila, el poder sentirse uno cómoda con uno mismo, el poder disfrutarse uno aunque sea una bailada en una fiesta de cumpleaños. Usted no se lo puede disfrutar. Al noventa por ciento de mamás cuidadoras nos pasa eso, usted no se puede disfrutar una fiesta" $\left(\mathrm{EG}_{2}\right)$

Ahora bien, las relaciones familiares se afectan porque no todos en casa están dispuestos a asumir el cuidado, a aceptar a la persona con discapacidad, ocuparse de "cargas" que creen que no les competen. En la mayoría de los casos nadie está dispuesto a sacrificar su tiempo, vida y dinero; esto solamente lo hacen en las narrativas de esta investigación las madres quienes, por el amor a sus hijos o hijas, aun sabiendo el sacrificio que deben asumir, se comprometen en cuerpo, mente y tiempo para mejorar la calidad de vida de ellos.

"Fue difícil para nosotros como familia; sin embargo, yo lo acepté con todo el amor del mundo, pero en el momento que me lo diagnosticaron con agenesia de cuerpo calloso y que para toda la vida iba a tener un retraso a nivel cognitivo, mi esposo se fue, me abandonó diciendo que yo era la culpable por querer tener hijos tan vieja" $\left(\mathrm{EC}_{3}\right)$

"Por la discapacidad de mi hijito lindo se dañó la relación mía con mi mamá. Me reprocha mucho que no tengo nada, me dice en ocasiones que soy una inútil, que nunca producí dinero para vivir bien" $\left(\mathrm{EG}_{3}\right)$

"Sé que él me absorbe mucho, absorbe todas mis energías, ya no tengo amigos con quien hablar y no salgo a ningún lado, solo al parque con el niño para que se chupe un helado, hasta ya se me olvidó cómo es una piscina, cómo es una quebrada, ya se me olvidó cómo es el calor de tierra caliente. Nunca hay plata para pasear ni con mi hijo y ni sola; el tener un hijo así frustra la vida de alguien y, en este caso, se frustró la mía. Al menos viví en mi juventud. Me da tristeza con mis hijas el haber adquirido una responsabilidad tan grande, porque son ellas las que compran todo al niño, la ropita, zapatos, todo lo que él necesite" $\left(\mathrm{EC}_{3}\right)$

"A mi esposo no se le acabaron los amigos porque él se queda con ellos y juega fútbol y comparte una que otra cerveza. En cambio a mí sí se me acabaron las amigas porque yo sí no puedo salir porque con quién dejo la niña, y llevarla no puedo. Nadie la soporta" $\left(\mathrm{EG}_{5}\right)$ 
En la incidencia de la calidad de vida familiar se observa que otra situación que afecta es el factor económico, ya que el cuidado de los niños y niñas con discapacidad requiere de tiempo y dinero. Si los cuidadores trabajan para conseguir dinero no pueden dedicar tiempo suficiente al cuidado y si, por el contrario, cuidan del niño o niña, no pueden satisfacer las necesidades básicas a nivel económico y social. Una muestra de ello es que "[...] estos cuidadores necesitan muchas cosas: reconocimiento de que están haciendo un trabajo; asistencia, tanto humana como financiera, oportunidades para encontrar un empleo satisfactorio y para poder participar en la vida política y social". (Nussbaum, 2007, p. 111).

"Mi marido trabaja pero la economía no alcanza, porque no alcanza el sustento para la casa. Vuelvo y digo, son muchos gastos los de la casa más con el nene, pues con el niño con discapacidad uno tiene muchos gastos, bastantes gastos para las citas y para las terapias" $\left(\mathrm{EG}_{1}\right)$

"Una de esa necesidades es poder trabajar, colaborarle mucho a mi marido. Sí, porque lo que él gana es poco. Una de dos: o él ganara un poquito más, o yo poder trabajar, colaborarle y ayudarle bastante a él" $\left(\mathrm{EG}_{1}\right)$

"Me queda duro salir y trabajar. Y con quién dejo mi hijo. Porque si lo dejo, que así he hecho que he buscado he mirado quién me lo cuide, y eso no se me comprometen a cuidar al niño" $\left(\mathrm{EC}_{1}\right)$

"Personas que a él lo han visto convulsionar no saben qué hacer en las convulsiones, no saben qué hacer con el niño, no se me comprometen a cuidar al niño ni a nada de eso, y que y me queda muy duro entonces por eso no ayudarle a mi marido económicamente. Nos queda también duro comprarles a los niños porque ellos también necesitan lo que es la ropa que los zapatos que los pañales porque lo pañales toca estar permanentemente porque el niño está con pañales" $\left(\mathrm{EG}_{1}\right)$

"Ahora otra de las dificultades que más se tiene, es no tener un trabajo estable, a usted en que empresa lo reciben trabajando dos días en la semana y que le paguen un salario mínimo, ninguna empresa" $\left(\mathrm{EC}_{2}\right)$

"Me encantaría sí trabajar pero quién lo cuida. Siempre está la barrera ahí. Quién, quién se hace cargo, Mis hijas necesitan una nutritiva alimentación, no se las puedo dar porque, porque no tengo trabajo, que las niñas necesitan un buen vestir, un vestir digno, no puedo porque, porque no tengo trabajo, mis hijos y yo y mi hijo nos gustaría salir a pasear pero no podemos salir porque, porque no tengo, no tenemos un recurso económico el cual pueda yo sacarlos" $\left(\mathrm{EC}_{2}\right)$

"Son tantas las dificultades para poder trabajar. Quién lo cuida. Si pago quien me lo cuida medio sueldo se me va a quedar para cuidarlo, porque una persona, nadie se hace cargo de él nadie, nadie, nadie se hace cargo de una persona con condición de dificultad. Nadie, o sea, quien lo haga tiene que ser una enfermera y las enfermeras están cobrando entre 60 y 70 mil pesos, por tres cuatro horas. O sea, tendría uno que ganarse cinco millones de pesos para poder pagar una enfermera particular, y eso el Estado no lo ve" $\left(\mathrm{EC}_{2}\right)$ 
"Como pide los del bienestar familiar, el ICBF me ve así como estoy viviendo en las condiciones que yo vivo, ellos dicen que esto no es un hogar digno para un niño con dificultad que yo vivo en hacinamiento, yo no tengo para pagar un arriendo" $\left(\mathrm{EC}_{2}\right)$

"Si el papá de las niñas, mi esposo, no está trabajado, pues actualmente estamos mal económicamente no tenemos para nada, nosotros le pagamos arriendo a mi papá y estamos colgados" $\left(\mathrm{EC}_{4}\right)$

"La falta de un trabajo estable para mi esposo porque la economía es difícil, yo con lo que me gano en el jardín solo alcanza para comer, estamos endeudados en el arriendo y la ropita de las niñas se las regalan, no podemos llevarlas a un parque porque no hay plata" $\left(\mathrm{EC}_{4}\right)$

En estas familias otros miembros deben sacrificar tiempo, espacio, dinero, atención y oportunidades, porque el niño o niña con discapacidad requiere del cuidado permanente del cuidador; es decir, la calidad de vida de los otros miembros de la familia se ve afectada cuando el niño requiere de unos cuidados, medicamentos, aditamentos y ayudas técnicas costosas que debe generar el cuidador sacrificando otras necesidades o gustos de la familia.

"Si nosotros salimos al parque también es un poquito duro, porque si queremos comprar un helado, no hay para la comida, si hay plata para la comida no hay para el helado ni para la salida del parque y para sacarlos al parque para que solamente jueguen y no gastarles nada, mejor no sacarlos y que se queden en la casa porque esa es la realidad" $\left(\mathrm{EG}_{1}\right)$

"Siempre nos queda difícil y pesado tanto para él como para mí. Nos queda pesado sostener a cuatro nenes que para los pañales, que para la alimentación, que para el arriendo, que para los servicios" $\left(\mathrm{EC}_{1}\right)$

"La realidad es que nos queda también muy duro comprar a veces de la casa, comprar lo que uno necesita para la casa, porque mi marido, vuelvo y digo, mi marido no tiene, no le alcanza para comprar lo de la casa, lo que uno necesita" $\left(\mathrm{EG}_{1}\right)$

"El no poder trabajar, el no poder colaborar económicamente, de poderle comprar a mi hijo, a mis hijos, cosas que yo quiero, irme al Jaime Duque, que yo me quiero ir al Simón Bolívar, que yo me quiero, mamá, irme a Santa Marta, a Girardot. Por lo menos aquí a Villeta, no se puede porque el bolsillo no lo da, la situación económica está terrible" (EC2)

"No se puede un paseo, usted no se puede disfrutar una piscina, usted no se puede disfrutar una salida a la calle, porque el niño no puede, el niño no puede, el niño no quiere, económicamente no se puede. Son muchas las dificultades, o sea, son muchas la barreras, uno se priva de muchas cosas, de salir aunque sea a un parque, porque ya el frío, el calor, el viento, los quemo, los enfermo. Son muchas las dificultades" $\left(\mathrm{EG}_{2}\right)$

"No podemos compartir en familia en un lugar ajeno a la casa, pero porque no hay plata" $\left(\mathrm{EC}_{4}\right)$

"Yo siento que el papá descuida a mi otra hija por consentir y estar tan pendiente de Evelyn. Me da miedo que cuando la niña crezca nos reproche esa falta de amor" $\left(\mathrm{EC}_{4}\right)$ 
"Pues la discapacidad influye mucho porque nosotros no tenemos una buena calidad de vida tanto mental como económica. Digo metal porque vivimos atemorizados, angustiados de poder perder a nuestra hija, y es una angustia mental que no le deja pensar a uno más allá, pero es por culpa de esas convulsiones. Y mi esposo ha perdido trabajos porque como él la quiere tanto, la ama, cuando la niña se enferma o tiene alguna recaída, él siempre quiere estar ahí al lado de ella" ( $\left.\mathrm{EG}_{4}\right)$

"Mi esposo no nos saca a pasear, ni a un parque porque dice que la plata que se gana solo son para los gastos de la casa no para botarla en bobadas. Yo sé que la niñas también necesitan de salir y conocer" $\left(\mathrm{EG}_{5}\right)$

"Con mi esposo peleamos con mucha frecuencia porque él, en lugar de ayudarme, lo que hace es que yo tenga más carga para la crianza de mis hijas que cada día que pasa sea más difícil. A la hermanita le da pavor acercársele porque siempre le pega. Nunca pero nunca comparten, siempre tienen que estar separadas" $\left(\mathrm{EC}_{5}\right)$

El cuidado de los niños y niñas con discapacidad afecta la salud de las madres. En algunos casos, físicamente por agresiones de los niños y niñas, en otros, por el desgaste físico que realizan a diario o emocionalmente porque sienten cargas de trabajo, generando malestar a nivel familiar.

"Mis hijas ahora las dos trabajan y son las que me dan plata. Ellas quieren mucho a Yeisito pero él sigue muy brusco y las muerde. A mí también me muerde, tengo los brazos muy cicatrizados, pero yo a él lo amo y me aguanto todo, tengo mucha fortaleza, pero a mí a veces me da pesar con mis dos hijas que me tengan que ayudar económicamente y que no hubieran podido terminar sus estudios" $\left(\mathrm{EC}_{3}\right)$

"Él duerme conmigo y yo no puedo descansar plenamente, no me quedo dormida profunda porque a mí me da miedo que él se despierte y me muerda" $\left(\mathrm{EC}_{3}\right)$

El cuidado constantemente hace que las madres conlleven las "[... cargas que todo eso supone para los cuidadores de las personas dependientes" (Nussbaum, 2007, p. 111), pues si bien las madres cuidadoras aman a sus hijos, se preocupan por ellos, hacen cada día su mejor trabajo, se esfuerzan por mejorar a diario su calidad de vida, son conscientes de que este cuidado ha generado en ellas algunas consecuencias a nivel de salud, afectivo y económico; constantemente se ven afectadas por el estrés o carga del cuidado, han dejado de vivir sus vidas por encargarse del cuidado, la atención y la satisfacción de necesidades de los niños, y sus presupuestos diarios giran en torno a lo que el niño o niña necesite.

"No piensan en uno como cuidador, porque uno de cuidador también se enferma, le da hambre, le da cansancio. O sea, solo piensa si el niño y nosotras como cuidadoras, ¿qué?” $\left(\mathrm{EG}_{2}\right)$

"Nosotras dejamos toda nuestra vida, nuestra juventud, nuestras, todo lo dejamos detrás de ellos, y ¿nosotras qué? ¿Nunca piensan en nosotras como cuidadoras?” $\left(\mathrm{EC}_{2}\right)$ 
"El niño cuando me lo diagnosticaron era un bebé y mis dos hijas de 15 y 17 años, y yo sin trabajar. Mi esposo se fue, dejando en mi sola esa responsabilidad, una responsabilidad que yo veía muy difícil, pero la veía difícil porque no tenía trabajo y nunca había trabajado. Mis dos hijas en el colegio, tocaba pagar arriendo y servicios, y no tenía nada ni una moneda ni para comer, el niño se empezó a enfermar de los bronquios y yo corra para todos lados pidiéndole a los vecinos, mi hija mayor que apenas tenía 17 añitos le tocó salirse de estudiar, pero gracias a Dios consiguió trabajo en un almacén vendiendo ropa y lo que se ganaba era todo para la casa porque yo no podía trabajar por el niño" $\left(\mathrm{EC}_{3}\right)$

"Uno como cuidador no puede descansar tranquilamente en las noches. Ella dormía en el medio de mi esposo y mío pero eso se sentaba dormida y se tiraba fuerte y nos pegaba en la cabeza. Por lo tanto, mi esposo decidió en salirse de la cama porque él tenía que madrugar para trabajar y la niña no lo dejaba descansar; por lo tanto, ahora soy yo la que duerme con ella y ella a mí no me deja dormir" $\left(\mathrm{EG}_{5}\right)$

"Nadie de mi familia me ayuda, me enseña. Todos la rechazan y me rechazan a mí, a mí no me volvieron a invitar a ningún lado que porque la niña no se sabe comportar. Eso es muy verraco; yo perdí a mi familia y a mis amigos cuando Heidi tenía un año de edad que fue cuando empezó a adquirir esos comportamiento de los autistas" $\left(\mathrm{EG}_{5}\right)$

Si bien en algunas situaciones las "cargas" que generan los niños y niñas con discapacidad son alivianadas por entidades como el jardín, ellas deben estar todo el tiempo disponibles para asistirlos cuando, por alguna situación particular que afecta al niño, debe ser retirado de dicho espacio y continuar al cuidado de ellas en casa.

"Es duro mendigarle al Estado una ayuda, un comedor, un jardín, un, un o sea lo que ellos dan son una limosnas, nosotros tenemos que vivir con una limosna, no es porque les nazca sino es porque les toca, porque la ley dice así, por las leyes de extranjería dicen que las personas con condición de discapacidad tiene que cuidarlos" $\left(\mathrm{EC}_{2}\right)$

"Yo me siento impotente de no saber cómo enseñarle a la niña hacer cosas a que aprenda cosas para su vida diaria y su bienestar" $\left(\mathrm{EG}_{5}\right)$

Cuando una familia se encuentra en condiciones económicas difíciles cualquier ayuda que provea el Estado es de gran valor para los cuidadores y cuidadoras, ya que los requerimientos a nivel nutricional, de salud y de cuidado de algunos niños y niñas demanda tiempo, dinero, recursos y espacio; “[...] a mujer que realiza estos trabajos puede confiar en recibir alguna ayuda de la familia extensa o de la comunidad; en otros, no" (Nussbaum, 2007, p. 114), ya que el Estado no cumple a cabalidad con dichas necesidades.

"Son los vecinos que también nos colaboran a nosotros con ropita, nos regalan las ropa, zapatos, pero, como vuelvo y digo, eso es ropita ya usada y eso, siempre es duro colocarle la ropa ya usada a los niños que otros se la coloque, pues los vecinos la hacen con buena voluntad. Sí, yo les agradezco con el alma, pero no hay como nosotros poderles brindar también a ellos" $\left(\mathrm{EG}_{1}\right)$ 
"El levantarme todos los días, domingo, festivos, lo que sea y a buscarme a rebuscarme a mendigar un plato de comida, un... para sostenerlos a ellos, a donde sea en iglesias o en ONG, donde sea tengo que irme a rebuscarme lo que necesita el niño, lo que requiere la alimentación de mis hijos, a mí me toca mendigar puerta a puerta para poder sacar mi hijos adelante" $\left(\mathrm{EC}_{2}\right)$

"Al irse mi esposo, mis hijas se vieron en la obligación de salirse de estudiar y empezar a trabajar para ayudarme, porque por la discapacidad de mi hijo yo no puedo trabajar por estar pendiente de él, de sus necesidades y de sus comportamientos. Al yo no trabajar el futuro de mis hijas se vio truncado, sus sueños de llegar a ser profesionales se frustró, nunca trabajé y tampoco aprendí hacer nada porque cuando me casé mi esposo me decía que yo solo tenía que preocupar por la casa y el cuidado de mis hijas" $\left(\mathrm{EG}_{3}\right)$

Otra situación que incide en la calidad de vida de las familias de personas con discapacidad son los aditamentos que se requieren, buscando eliminar las barreras de accesibilidad y participación en los diferentes escenarios sociales, educativos, culturales y políticos. La Política Pública de Discapacidad (2007) manifiesta que todas las acciones integrales deben ser dinámicas en donde permita una relación e interacción entre los factores físicos, materiales y la acción humana para el goce de un ambiente saludable. Porque no solamente es la accesibilidad a una silla de ruedas para que el cuidador pueda transportar al niño a varios lugares, es también la necesidad de que los niños y niñas sean participativos en un ambiente social y territorial. Pero las cuidadoras no cuentan con dinero suficiente para adquirir los aditamentos por cuenta propia y lograr que ellos tengan una vida más participativa.

"En la casa también necesita muchas ayudas, una es la silla en donde él se siente derecho y otra que es también la colchoneta especial para el niño también la necesito pero tampoco la pudo tener. No he podido ni nada de eso precisamente por la economía” $\left(\mathrm{EC}_{1}\right)$

"Si no es con demandas es con tutela para conseguir las cosas de ellos de la personas con dificultad" $\left(\mathrm{EG}_{2}\right)$

"Los insumos de él son costosos. Él utiliza pañal, él las cosas que el Estado no se lo da es muy, muy, hay barreras tan grandes que una para alcanzar esas ayudas son difíciles y el Estado dice no es que no hay, no es que no sabemos es que no es que sí, es que tal vez" $\left(\mathrm{EC}_{2}\right)$

\section{Categorías Emergentes}

\subsection{Sentimientos de temor y angustia por el futuro de sus hijos}

Las cuidadoras sienten temor solo con el hecho de pensar si ellas mueren o se enferman gravemente, quién cuidaría de sus niños o niñas con discapacidad, ya que sienten que ellos nunca se van a poder valer por sí solos y necesitan de alguien que los ayude a sus necesidades constantemente. Este temor nace porque sienten que están solas en las prácticas que generan en el cuidado, ya que son ellas las que se esfuerzan por realizar 
un cuidado necesario para mejorar la calidad de vida de cada niño y niña, y que son conscientes que dedican todo su tiempo a ese cuidado. Entonces las cuidadoras también tienen que soportar "[...] la pesada carga de la culpa de aquellos miembros de la familia que simplemente no pueden aportar la asistencia necesaria" (Nussbaum, 2007, p. 177). Aunque no pretenden que su hijo e hija con discapacidad llegue a tener una desprotección total porque ellas no están ahí, ya que si fallecen, ellos pueden llegar a ser institucionalizados si ningún otro miembro de la familia asume ese cuidado.

"El día de mañana yo me muero, que ese es el temor de uno de madre, y ellos van a quedar ahí vivos y quién los va a cuidar, ¿el Estado? ¿el Gobierno? ¿Quién los va a cuidar? Nadie. O sea si sus hijos no se hicieron cargo los botan en un centro geriátrico o los matan y quién los cuida" $\left(\mathrm{EC}_{2}\right)$

"Si el niño con dificultad se enferma, todos tienen que estar pendiente de él, pero si yo como cuidadora me enfermo, yo no puedo estar pendiente de mí porque yo tengo que estar pendiente de él. Entonces, ¿quién lo cuida? Nadie" $\left(\mathrm{EG}_{2}\right)$

"Nadie entiende al niño. Me da miedo cuando yo me muera qué irá a ser de mi hijo" $\left(\mathrm{EC}_{3}\right)$

\subsection{Sentimientos de frustración y vulneración de sus derechos}

Por otro lado, las cuidadoras de los niños y niñas con discapacidad se sienten frustradas, vulneradas, piensan que es una tarea difícil y en ocasiones no saben cómo pueden realizar un cuidado adecuado que, a la vez, establezca límites, normas y respeto. Además, piensan que están solas y les toca luchar solas para conseguir todo lo que los niños y niñas requieren, aunque la Política Pública de Discapacidad (2007) promueve que las personas con discapacidad y sus familias sean reconocidas en la búsqueda de bienestar para una inclusión humana, social, económica, cultural y política, en donde se les aporte, reconozca y garantice los derechos para lograr transformar la desigualdad social y que disfruten de una vida plena. Se sienten que no les han llegado esos recursos para el disfrute de su núcleo familiar.

"Un hijo, una persona en condición de discapacidad es terrible. O sea es duro, o sea una cosa sin palabras porque uno no sabe cómo expresarlo, qué decir es una cosa muy fuerte tanto psicológicamente" $\left(\mathrm{EG}_{2}\right)$

"No saber qué derechos tienen nuestros hijos, es por eso por ignorancia, por no leer, por no saber, por no instruirnos, por no tener una persona ahí que nos resuelva, nos entregue eso más menudito" $\left(\mathrm{EG}_{2}\right)$

"Es como si el Estado fuera ajeno de la situación que vivimos nosotros los cuidadores que no tenemos ni una consideración para pedir la citas que no son tan fáciles de conseguir" $\left(\mathrm{EG}_{3}\right)$

"Cuando la niña nació me la diagnosticaron a los seis meses con microcefalia y eso fue duro, frustrante para mí, yo solo lloraba cada día mirándola a los ojos y haciéndome miles de preguntas" $\left(\mathrm{EC}_{4}\right)$ 
"Yo veo una dificultad grande al no saber cómo le voy a enseñar a quitarle el pañal, no sé cómo enseñarle a que camine sola, a que no muerda a nadie, a que, a que no, mejor dicho a que comparta con la hermanita" $\left(\mathrm{EG}_{5}\right)$

\subsection{Prácticas culturales de discriminación}

Al igual, las cuidadoras sienten que toda la sociedad aún no se encuentra sensibilizada y preparada para aceptar a las personas con discapacidad, ya que cuando las cuidadoras se dirigen a algún lugar con su hijo o hija, sienten la mirada de las personas en forma de rechazo, burla y lásstima. También consideran que la política pública todavía no adecúa, en su totalidad, los espacios territoriales y de movilización para que las cuidadoras y cuidadores puedan trasportarse con sus hijos e hijas a cualquier lugar sin mostrar lástima hacia la sociedad; en este sentido, la reestructuración del espacio público es esencial para la dignidad y el autorespeto de las personas con discapacidad.

En resumen, la tarea de incluir a las personas con discapacidad en el espacio público "[...] es una tarea pública, que requiere una planificación pública y un uso público de los recursos” (Nussbaum, 2007, p. 175). Es la sociedad quien debe incentivar la inclusión y, así, facilitar el mejoramiento de las capacidades de las niños y niñas con discapacidad.

"Me incomoda que le digan al niño discapacitado o que le digan especial es niños con dificultad o sea es para mí es incómodo escuchar eso y ver como miran a mi hijo en la calle como un bicho raro que tan feo que, que pecado hay pobrecito o sea eso se ve horrible ante el ámbito de la sociedad de la calle" $\left(\mathrm{EC}_{2}\right)$

\section{Conclusiones}

Se evidencia que la concepción que las madres de los niños y niñas con discapacidad tienen del cuidado está relacionada con la disposición de tiempo, comprensión, protección, compañía, amor, atención y aceptación, comprometiéndose a diario con el afecto, espacio y tiempo para brindar todo lo que requieran sus hijos e hijas en aras de satisfacer sus necesidades e intentar brindar una asistencia básica para garantizar su calidad de vida.

Así mismo, esta comprensión está ligada a la satisfacción de necesidades de sus hijos e hijas, ya que a diario las madres desempeñan este trabajo brindando un mayor vínculo afectivo hacia ellos y ellas; sin embargo, al conocer más a nivel interno las dinámicas familiares, se evidencia que, si bien el cuidado nace del amor hacia el niño o niña, también se percibe como una "carga" a nivel físico, económico y de tiempo para la cuidadora. Desde el inicio, las cuidadoras asumieron el cuidado de sus hijos e hijas, afirmando que buscan mejorar la calidad de vida, y procuran satisfacer sus necesidades a nivel de salud, alimentación, vestido, vivienda e incluso recreación. 
Las cuidadoras afirman que la concepción del cuidado parte no solo de las prácticas que a diario realizan, sino que además se relaciona con el apoyo a nivel institucional que les brinden, donde sus niños y niñas tengan una rehabilitación integral, sistema de salud óptimo y un lugar que les colabore con algunas horas diarias de cuidado en otro espacio, con el fin de que les fortalezcan las habilidades adquiridas y se generen otras nuevas, siempre procurando hacerles partícipes de diferentes escenarios sociales. Esto también ayudaría a que las madres cuenten con tiempo para ellas y, de esta manera, puedan encontrar oportunidades laborales y recibir alguna remuneración económica.

Es importante resaltar que, en las narrativas realizadas, la concepción de cuidado que tienen las madres de los niños y niñas con discapacidad es muy clara, en la cual piensan que son ellas quienes deben asumir este cuidado. Aunque desean que otras personas les colaboren, sienten que la responsabilidad es suya. An algunos casos, incluso, culpándose por la condición de su hijo o hija; se observa que son muy conscientes de que solo ellas como madres sacrifican lo que sea necesario para mantener a su hijo o hija y procurarles un bienestar integral.

En cuanto a las prácticas de cuidado, se observa que en pro de una mejor calidad de vida del niño o niña con discapacidad, las madres trabajan a diario en el cuidado para satisfacer sus necesidades básicas, y generan estrategias que les permiten enseñarles algunos conocimientos. Esto lo hacen, generalmente, en términos de independencia, ya que son conscientes e incluso temerosas del futuro de su hijo e hija, porque no saben qué será de la vida de ellos y ellas cuando, por alguna razón, la madre falte.

Así mismo, se observa que para las madres el cuidado de su hijo o hija es percibido como un desgaste, si bien tienen toda la disposición para desempeñar estas funciones, afirman que el sistema de salud, las entidades de educación y en general de inclusión social, al que podrían acceder los niños o niñas con discapacidad requieren de un tiempo y trabajo permanente por parte de ellas, y que a pesar de que se esmeren por lograr la inclusión de su hijo e hija a los diferentes espacios de participación, en ocasiones deben llevar a cabo procesos legales (derechos de petición y/o tutelas)que les garanticen a sus hijos e hijas los derechos que tienen como ciudadanos, ya que como dicen las madres mismas "falta mucha sensibilización por las condiciones de discapacidad que tienen estos niños y niñas".

En estas prácticas de cuidado que desarrollan a diario las madres y debido al difícil acceso a los sistemas de salud y educación, ellas se convierten en terapeutas, médicas, pedagogas, abogadas, entre otras. Las madres comentan que mientras en algunos casos ciertas personas les han enseñado cómo cuidar, corregir, enseñar, educar y criar a su niño o niña, en otros han sido conocimientos empíricos que han ido descubriendo y aprendiendo desde la práctica diaria. 


\section{ČIF́F́ 26}

ISSN: 0124-3551 / Año 17, No 26 / enero-junio / pp. 109-148

Otro aspecto que afecta las prácticas de cuidado diario es la situación económica que viven estas familias, ya que los requerimientos a nivel nutricional, de salud y de cuidado de algunos niños y niñas con discapacidad demandan tiempo, espacio, recursos y mucho dinero. Sin embargo, al interior de cada familia, les brindan a los niños y niñas lo que esté al alcance, dejando de lado algunos aspectos muy importantes que, por la situación económica, no pueden proporcionar.

Es de resaltar que la incidencia en la calidad de vida de las familias de niños y niñas con discapacidad se ve afectada en la medida que las prácticas de cuidado requieren dinero, dedicación, y un compromiso de las 24 horas del día, generando, a nivel familiar, dinámicas que afectan la tranquilidad y armonía entre los diferentes miembros de la familia. Si bien la vida familiar se afecta debido a las necesidades de atención del niño o niña, fuera de casa los demás entes de la familia llevan una vida "normal"; usualmente, la única persona que no puede llevar una vida "normal" es la madre del niño o niña, ya que es ella quien ejerce el cuidado. Como ellas han afirmado en las entrevistas, "[...] dejan de vivir sus vidas, por vivir la de sus hijos o hijas con discapacidad".

Si bien los demás miembros de la familia en algún momento desean colaborar con el cuidado del niño o niña, no lo asumen todo el tiempo; primero, por el temor que genera no saber cómo hacerlo o cómo manejar las situaciones que se pueden presentar a diario y, segundo, porque deben suplir otras necesidades, ya que si los otros miembros de la familia trabajan para conseguir dinero no pueden dedicar tiempo suficiente al cuidado. O, por el contrario, si todo el tiempo cuidan del niño o niña, no pueden trabajar y, por consiguiente, no logran satisfacer las necesidades básicas de un hogar.

Otra situación que se hizo evidente es que el cuidado de los niños y niñas con discapacidad afecta la salud de las madres cuidadoras, ya que los niños y las niñas requieren de un desgaste físico y emocional; físico porque hace que las madres se enfermen continuamente y emocional porque se sienten cargas de trabajo, generando malestar a nivel familiar. En ocasiones, la actitud de las madres es irritable, sensible o molesta, ya que el hecho de no sentir apoyo o de no ver que el avance de su hijo sea rápido genera en ellas estas molestias.

Si bien las madres cuidadoras aman a su hijo o hija, se preocupan constantemente por su bienestar, hacen cada día su mejor trabajo, se esfuerzan por mejorar a diario su calidad de vida, también son conscientes de que este cuidado ha generado en ellas algunas consecuencias a nivel de salud, ya que se ven afectadas por el estrés que genera dicho cuidado, a nivel afectivo, en la medida en que han dejado de vivir sus vidas por encargarse del cuidado, la atención y la satisfacción de necesidades, y a nivel económico, pues sus presupuestos diarios giran en torno a lo que el niño o niña con discapacidad necesite. 
Para finalizar, indudablemente la concepción que tienen y las prácticas que ejecutan las madres a diario en el cuidado afectan positiva o negativamente en la calidad de vida familiar, ya que, si bien se requiere del apoyo de un sistema de salud óptimo, entes externos que apoyen el cuidado y brinden estrategias que les enseñen como asumir ciertas prácticas de cuidado, son ellas quienes deben por el resto de su vida comprometerse con el cuidado de su hijo o hija.

Así mismo, se observa que el Estado está en deuda con las personas con discapacidad y con las madres cuidadoras, ya que, pese a que sus políticas mencionan y apoyan los derechos de las personas con discapacidad, en realidad a los niños y niñas no se les garantizan oportunidades reales en los diferentes escenarios sociales, evidenciando aún grandes barreras para el aprendizaje y la participación. Y las madres cuidadoras, aun en la garantía de derechos, no son tomadas en cuenta para auxilios económicos que permitan suplir las necesidades de un hogar. Ellas ejercen un trabajo de cuidado no remunerado y por encontrarse permanentemente en este cuidado no logran vincularse laboralmente. Si encontraran apoyo por parte del Estado, que brinde garantías económicas para ellas, no sentirían que el cuidado es una carga sino un compromiso de amor, dedicación y las madres mejorarían su calidad de vida y la del núcleo familiar. 


\section{Referencias}

Amoni, G. (2011). Autismo Infantil una clínica desde el psicoanálisis. Argentina; Editorial Homo Sapiens.

Baquero, M. I. (2009). El enfoque diferencial en discapacidad: un imperativo ético en la revisión del plan de ordenamiento territorial de Bogotá D.C. Disponible en: www.viva.org.co/cajavirtual/svc0168/articulo0007.pdf

Baquero, M. I. (2013). El enfoque diferencial en discapacidad como categoría de cultura política para el reconocimiento y la inclusión de personas con discapacidad, víctimas del conflicto armado interno Colombiano. En: La Acción Social en los Derechos Humanos.

Baxter, P. (2009). Microcefalia adquirida: causas, patrones, efectos motores y sobre CI, y alteraciones del crecimiento asociadas. Disponible en: zl.elsevier.es/es/revista/pediatrics-10/ pdf/13142506/S300/

Coffey, A. \& Atkinson, P. (2004). Encontrar el sentido de los datos cualitativos. Medellín: Editorial Universidad de Antioquia.

Castro, A. \& Vizcaíno, R. (2012). Cartilla de cero a siempre, Atención Integral a la primera infancia. Apoyo de la comisión intersectorial de la primera infancia.

Constitución Política de Colombia. (1991). Disponible en: web.presidencia.gov.co/ constitucion/index

Córdoba, L., Gómez, J. \& Verdugo, M. (2010). Calidad de vida familiar en personas con discapacidad: un análisis comparativo. Disponible en: www.scielo.org.co/pdf/rups/v7n2/ v7n2a06.pdf

Cruz, G. (2010). Análisis de roles y funciones que asumen las madres de un hïo con síndrome de Down. México: Universidad Autónoma de México.

Ortega, P. (2012). Cambios en la dinámica familiar con hijos con discapacidad. México: Universidad Autónoma de México. Disponible en: www.psicologiacientifica.com/ hijos-con-discapacidad-cambios-familia

Fischer, D., Aguilera, S., Enriquez, G., Rodríguez, G., Medina, L. \& Terra, R. (2003). Centro de Referencia Perinatal Oriente. Disponible en: www.cerpo.cl/_items/ File_002_00355_0024.pdf

Decreto 470 (2007) Política pública de discapacidad. Disponible: wrercalcaldiabogota.gov. co/sisjur/normas/Norma1 
Flick, U. (2007). Introducción a la Investigación Cualitativa. Madrid: Ediciones Morata.

ICBF. (2006). Ley 1098 Código de infancia y adolescencia. Disponible en: www.icbf.gov. co/portal/page/portal/.../CIyA-Ley-1098-de-2006.pdf

López, M. (2005). Insuficiencia motora de origen cerebral (IMOC). Disponible en: www.efisioterapia.net

Marroquin, M., García, J. \& Peña, R. (2011). Tesis narrativas de redes familiares sobre la crianza de la primera infancia. Especialización el consultoría de familias y redes sociales. Bogotá: Universidad de La Salle.

Moncayo, E. (2006). Manual de epilepsia. México: Editorial Trillas.

Noddings, N. (2009). La educación moral. Buenos Aires.

Nussbaum, M. (2007). Las Fronteras de la fusticia. Barcelona: Paidos. (2005). El cultivo de la humanidad. Barcelona: Paidos.

Nussbaum, M. \& Sen, A. (1996). La Calidad de Vida. México: Fondo de Cultura Económica.

ONU. (2006). Convención sobre los derechos de las personas con discapacidad y protocolo facultativo de las Naciones Unidas. Disponible en: www.un.org/esa/socdev/enable/documents/ tcconvs

Opina, F. (2007). Familia, sociedad y la calidad de vida de las personas con discapacidad, Diplomado de psicología de la salud. Bogotá: Universidad de La Sabana, Facultad de Psicología. Disponible en: intellectum.unisabana.edu.co:8080/jspui/ bitstream/10818/.../131346.p

Sen, A. (1999). Desarrollo y libertad. Buenos Aires: Editorial Planeta.

Secretaría Distrital de Integración Social, San Cristóbal: Disponible en: www.integracionsocial.gov.co/modulos/contenido/default.asp?idmodulo.

Secretaría de Integración Social. (2012). Atención Integral a Personas con Discapacidad, Familias, Cuidadores y Cuidadoras - Cerrando Brechas. Disponible en: www.integracionsocial.gov.co/.../proyectosbogotahumana/721\%20Atenc.

Unicef. (2006). Convención de los Derechos del Niño. Disponible en: www2.ohchr.org/spanish/law/crc.htm 


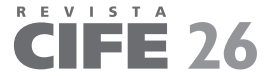

ISSN: 0124-3551 / Año 17, No 26 / enero-junio / pp. 109-148

Úbeda, B. (2009). Calidad de vida de los familiares: evolución mediante un cuestionario. Barcelona: Universidad de Barcelona. Disponible en: www.tdx.cat/bitstream/10803/2081/1/ IUB_TESIS.pdf

Verdugo, M. \& Schalock, R. (2011). Modelo de calidad de vida aplicado a la atención residencial de personas con necesidades complejas de apoyo. Madrid: Instituto de Mayores y Servicios Sociales. Disponible en: www.imserso.es/InterPresentl/groups/imserso/documents/binario/doc_tec_21020.pdf.

Torres, D. (2011). Narrativas de la pautas de crianza en la primera infancia en el Municipio de Anolaima. Bogotá: Universidad de la Salle, Facultad de Ciencias Sociales. 